\title{
Activation of the transient receptor potential M2 channel and poly(ADP-ribose) polymerase is involved in oxidative stress-induced cardiomyocyte death
}

\author{
K-T Yang ${ }^{1,5}$, W-L Chang ${ }^{2,5}$, P-C Yang ${ }^{3}$, C-L Chien ${ }^{4}$, M-S Lai ${ }^{4}$, \\ M-J Su${ }^{, 2}$ and M-L Wu*,1 \\ ${ }^{1}$ Institute of Physiology, College of Medicine, National Taiwan University, \\ Taipei, Taiwan \\ 2 Institute of Pharmacology, College of Medicine, National Taiwan University, \\ Taipei, Taiwan \\ ${ }^{3}$ Department of Internal Medicine, National Taiwan University Hospital, National \\ Taiwan University, Taipei, Taiwan \\ ${ }^{4}$ Institute of Anatomy and Cell Biology, College of Medicine, National Taiwan \\ University, Taipei, Taiwan \\ 5 These authors equally contributed equally to this work \\ * Corresponding authors: M-L Wu, Institute of Physiology, College of Medicine \\ National Taiwan University, No. 1, Sec. 1, Jen-Ai Road, Taipei, Taiwan. \\ Tel: + 8862 23123456x8242; Fax: + 8862 23224330; \\ E-mail: mlw@ ha.mc.ntu.edu.tw or M-J Su, Institute of Pharmacology, College \\ of Medicine, National Taiwan University, No. 1, Sec. 1, Jen-Ai Road, Taipei, \\ Taiwan. Tel: + 8862 23123456x8317; Fax: + 8862 23971403; \\ E-mail: mjsu@ha.mc.ntu.edu.tw
}

Received 24.5.05; revised 26.9.05; accepted 11.10.05; published online 18.11.05 Edited by $\mathrm{P}$ Vandenabeele

\begin{abstract}
Overproduction of reactive oxygen species is one of the major causes of cell death in ischemic-reperfusion (I/R) injury. In I/R animal models, electron microscopy (EM) has shown mixed apoptotic and necrotic characteristics in the same cardiomyocyte. The present study shows that $\mathrm{H}_{2} \mathrm{O}_{2}$ activates both apoptotic and necrotic machineries in the same myocyte and that the ultrastructure seen using EM is very similar to that in $\mathrm{I} / \mathrm{R}$ animal studies. The apoptotic component is caused by the activation of clotrimazole-sensitive, $\mathrm{NAD}^{+}$/ADP ribose/poly (ADP-ribose) polymerase (PARP)-dependent transient receptor potential M2 (TRPM2) channels, which induces mitochondrial $\left[\mathrm{Na}^{+}\right]_{\mathrm{m}}$ (and $\left[\mathrm{Ca}^{2+}\right]_{\mathrm{m}}$ ) overload, resulting in mitochondrial membrane disruption, cytochrome $c$ release, and caspase 3-dependent chromatin condensation/fragmentation. The necrotic component is caspase 3 -independent and is caused by PARP-induced [ATP] $/$ NAD $^{+}$depletion, resulting in membrane permeabilization. Inhibition of either TRPM2 or PARP activity only partially inhibits cell death, while inhibition of both completely prevents the ultrastructural changes and myocyte death.

Cell Death and Differentiation (2006) 13, 1815-1826.

doi:10.1038/sj.cdd.4401813; published online 18 November 2005
\end{abstract}

Keywords: mitochondrial $\mathrm{Na}^{+}$overload; TRPM2; PARP; apoptosis; necrosis

Abbreviations: TRPM2 channel, transient receptor potential M2 channel; ROS, reactive oxygen species; EM, electron microscopy; I/R injury, ischemic-reperfusion injury; $\left[\mathrm{Na}^{+}\right]_{\mathrm{m}}$, mitochondrial $\mathrm{Na}^{+}$levels; $\left[\mathrm{Ca}^{2+}\right]_{\mathrm{m}}$, mitochondrial $\mathrm{Ca}^{2+}$ levels; CsA, cyclosporin A; PTP, permeability transition pore; cytC, cytochrome $c$; PARP, poly(ADP-ribose) polymerase; ADPR, ADP ribose; PAR, poly(ADP ribose); PARG, poly(ADP-ribose) glycohydrolase; NA, nicotinamide; 3-AB, 3-aminobenzamide; DPQ, 3,4-dihydro-5-[4-(1-piperidinyl)butoxy]-1(2H)-isoquinolinone; TUNEL, TdT-mediated dUTP-X nick end labeling; PI, propidium iodide; EthD-1, ethidium homodimer

\section{Introduction}

Overproduction of reactive oxygen species (ROS) is suggested to be responsible for myocyte death in ischemicreperfusion (I/R) animal models and in patients with $\mathrm{I} / \mathrm{R}$ injury. ${ }^{1,2}$ Different types of myocyte death during $\mathrm{I} / \mathrm{R}$ injury have been demonstrated, including apoptosis ${ }^{2-4}$ and necrosis. ${ }^{5,6}$

The hallmarks of apoptosis are usually an intact membrane, chromatin condensation, and nuclear fragmentation. ${ }^{7}$ The key events in the mitochondrial-dependent apoptotic pathway are the opening of the cyclosporin A (CsA)-sensitive permeability transition pore (PTP), resulting in the release of cytochrome $c$ (cytC) and other apoptogenic proteins, and in caspase 3dependent nuclear condensation/fragmentation..$^{4,8-10}$ ROSinduced mitochondrial $\mathrm{Ca}^{2+}\left(\left[\mathrm{Ca}^{2+}\right]_{\mathrm{m}}\right)$ overload is one of the major causes of PTP opening and cytC release, resulting in myocyte apoptosis. ${ }^{4,11}$

In contrast, necrosis is commonly characterized by an increase in plasma membrane permeability, release of intracellular proteins, and an absence of nuclear morphological changes. ${ }^{7,12}$ One major hypothesis for $\mathrm{l} / \mathrm{R}$-induced necrotic cell death is that ROS-induced DNA damage results in excessive activation of the nuclear repair enzymes, the poly(ADP-ribose) polymerases (PARPs). The activated enzymes accelerate $\mathrm{NAD}^{+}$cleavage into poly(ADP ribose) (PAR), and the regeneration of $\mathrm{NAD}^{+}$consumes ATP; so the pools of both $\mathrm{NAD}^{+}$and ATP are depleted, leading to necrosis by energy depletion. ${ }^{13}$ The use of PARP-1 null mice $\left(\mathrm{PARP}^{-1-}\right)$ or PARP inhibitors significantly reduces the $\mathrm{l} / \mathrm{R}$-induced infarct and peri-infarct (necrosis) area by 20-25\%. ${ }^{13-15}$

Electron microscopy (EM) shows that $1 /$ R-induced cell death does not result in a classic apoptotic or necrotic morphology, but in the appearance of both sets of characteristics in a single myocyte. ${ }^{16-18}$ The ultrastructure changes include EM-TdT-mediated dUTP-X nick end labeling (TUNEL)-positive nuclear fragmentation, plasma membrane permeabilization, and mitochondrial hernia with loss of cristae. This untypical mode of cell death is not restricted to cardiac cells, as it is also seen by EM in the rat brain cortex after cerebral artery occlusion. ${ }^{19}$ However, the molecular 
mechanism involved in this untypical cell death remains unclear.

Mammalian homologs of the Drosophila TRP channel gene encode a family of at least 21 ion channel proteins. The TRP family mainly consists of $\mathrm{Ca}^{2+}$ channels and can be divided into three subfamilies: classic (TRPC) channels, vanilloid receptor-like (TRPV) channels, and melastatin-like (TRPM) channels. $^{20,21}$ Transient receptor potential M2 channel (TRPM2) (previously LTRPC2 or TRPC7) is a $\mathrm{Na}^{+}$- and $\mathrm{Ca}^{2+}$-permeable nonselective cation channel and can be activated by exposing TRPM2-expressing cell lines to $\mathrm{H}_{2} \mathrm{O}_{2} \cdot{ }^{22-24}$ ADP ribose (ADPR) is suggested as a downstream messenger for TRPM2 opening, since one domain of TRPM2, which is homologous to NUDT9 ADR hydrolase, binds ADPR. $^{25}$ However, it has also been suggested that $\mathrm{NAD}^{+}$ directly gates the channel, ${ }^{22,26}$ since ${ }^{32} \mathrm{P}$-labeled $\beta-\mathrm{NAD}^{+}$ binds strongly to the C-terminus of TRPM2. ${ }^{22}$

Here, we show that oxidative stress $\left(20-100 \mu \mathrm{M} \mathrm{H}_{2} \mathrm{O}_{2}\right)$ also induces both modes of cell death in a singe cultured rat cardiomyocyte and that the ultrastructure changes are similar to those seen in I/R animal models. The $\mathrm{H}_{2} \mathrm{O}_{2}$-induced apoptotic changes involve TRPM2 opening, which results in mitochondrial $\left[\mathrm{Na}^{+}\right]_{\mathrm{m}}$ (and $\left[\mathrm{Ca}^{2+}\right]_{\mathrm{m}}$ ) overload, followed by mitochondrial membrane disruption, cytC release, and caspase 3-dependent nuclear condensation/fragmentation, while the necrotic changes are caspase 3-independent, but PARPdependent. Interestingly, inhibition of both TRPM2 and PARP activities totally abolishes $\mathrm{H}_{2} \mathrm{O}_{2}$-induced myocyte death.

\section{Results}

In the Supplementary Information, we show that functional TRPM2 channels are present in primary ventricular myocytes (Supplementary Figures $\mathrm{S} 1$ and S2). Since the electrophysiological properties of the $\mathrm{H}_{2} \mathrm{O}_{2}$-induced currents (Supplementary Figure $\mathrm{S} 3$ ) were very similar to those of the TRPM2 channel, the $\mathrm{H}_{2} \mathrm{O}_{2}$-induced $\left[\mathrm{Na}^{+}\right]_{i} /\left[\mathrm{Ca}^{2+}\right]_{i}$ overload (Supplementary Figure $\mathrm{S} 3 \mathrm{Ae}-\mathrm{g}$ ) could result from TRPM2 opening. If this were the case, the endogenous levels of $\mathrm{NAD}^{+}$and/or ADPR should be raised by exposure to $\mathrm{H}_{2} \mathrm{O}_{2}$. We tested this hypothesis in Figure 1.

\section{$\mathrm{H}_{2} \mathrm{O}_{2}$ increases intracellular levels of $\mathrm{NAD}^{+}$and ADPR}

The fluorescence of reduced pyridine nucleotides (NADH and NADPH) accounts for most of the cellular autofluorescence seen on excitation at $340 \mathrm{~nm}$, as oxidized pyridine nucleotides $\left(\mathrm{NAD}^{+}\right.$and $\mathrm{NADP}^{+}$) are nonfluorescent. ${ }^{27}$ The basal level of
$\mathrm{NAD}(\mathrm{P}) \mathrm{H}$ was normalized as $F / F_{0}=1\left(F_{0}=\right.$ basal fluorescence; Figure 1Ad). When cells were exposed to $100 \mu \mathrm{M}$ $\mathrm{H}_{2} \mathrm{O}_{2}$, the $\mathrm{NAD}(\mathrm{P}) \mathrm{H}$ levels started to decrease (i.e. $\mathrm{NAD}^{+}$ levels increased) at $1.9 \pm 0.2 \mathrm{~min}$, and maximum $\mathrm{NAD}^{+}$levels were seen at $7.3 \pm 0.8 \mathrm{~min}$ (Figures $1 \mathrm{Ad}$ and D). When $\mathrm{H}_{2} \mathrm{O}_{2}$ was continuously present for $60 \mathrm{~min}$, there was no recovery of $\mathrm{NAD}(\mathrm{P}) \mathrm{H}$ (Figure $1 \mathrm{Cb}$ ), indicating that $\mathrm{NAD}^{+}$is probably depleted at this time-point, since $[A T P]_{i}$ was depleted by exposure to $100 \mu \mathrm{M} \mathrm{H}_{2} \mathrm{O}_{2}$ for 60 min (see below). When rotenone was added in the continued presence of $\mathrm{H}_{2} \mathrm{O}_{2}$, $\mathrm{NAD}(\mathrm{P}) \mathrm{H}$ levels reversed rapidly (Figure 1Ac, $d$ and $D$ ), as rotenone inhibits complex I in the respiratory chain, causing maximal accumulation of $\mathrm{NAD}(\mathrm{P}) \mathrm{H}^{27}$ Addition of rotenone alone had little effect (Figure 1D). The $\mathrm{OH}^{\bullet}$ inhibitors, phenanthroline (Figure 1B and D) and DMTU (10 mM, not shown), completely inhibited the oxidation of $\mathrm{NAD}(\mathrm{P}) \mathrm{H}$ caused by $\mathrm{H}_{2} \mathrm{O}_{2}$, indicating that $\mathrm{OH}^{\bullet}$ induced an increase in $\mathrm{NAD}^{+}$levels (Figure 6).

Application of a PARP inhibitor, 3-aminobenzamide (3-AB), for $\sim 40 \mathrm{~min}$ (Figure $1 \mathrm{C}$ ) resulted in a small, but nonsignificant $(P>0.05$; Figure 1C), reduction in basal levels of $N A D(P) H$, indicating that little PARP was activated under basal conditions. However, in the presence of $\mathrm{H}_{2} \mathrm{O}_{2}, 3-\mathrm{AB}$ induced partial recovery of $\mathrm{NAD}(\mathrm{P}) \mathrm{H}$ (Figure $1 \mathrm{Cc}$ ), probably as a result of $\mathrm{NAD}^{+}$accumulation due to PARP inhibition, thus shifting the $\mathrm{NAD}^{+} \leftrightarrow \mathrm{NADH}$ equilibrium to the right (Figure 6). Prevention of $\mathrm{H}_{2} \mathrm{O}_{2}$-induced NAD ${ }^{+}$depletion by PARP inhibitors has also been demonstrated in other studies. ${ }^{28,29}$

After treatment with DNA-damaging reagents (e.g. $\mathrm{H}_{2} \mathrm{O}_{2}$ ), the enzyme poly(ADP-ribose) glycohydrolase (PARG) converts PAR (half-life of less than $1 \mathrm{~min}$ ) into mono(ADPR). ${ }^{13,30,31}$ Since anti-PAR antibody only recognizes the polymer, $^{32}$ to prevent PAR degradation into ADPR, the cells were fixed with trichloroacetic acid (see Supplementary Methods). Compared to the untreated control (Figure 1Ea), a marked increase in nuclear PAR immunoreactivity was seen in myocytes exposed for $5-20$ min to 20 or $100 \mu \mathrm{M} \mathrm{H}_{2} \mathrm{O}_{2}$ (Figure 1Eb-d), the immunoreactivity decreasing after $30 \mathrm{~min}$ exposure (Figure 1Ed). Moreover, phenanthroline, rotenone, 3,4-dihydro-5-[4-(1-piperidinyl)butoxy]-1(2H)-isoquinolinone (DPQ), or 3-AB largely inhibited the PAR formation seen after 20 min exposure to $100 \mu \mathrm{M} \mathrm{H}_{2} \mathrm{O}_{2}$ (Figure 1Ed), indicating that these chemicals effectively prevented PARP-activated PAR formation. The above results (Supplementary Figures S1-S3 and Figure 1) therefore indicate that the TRPM2 may be activated by $\mathrm{H}_{2} \mathrm{O}_{2}$-induced $\mathrm{NAD}^{+} / \mathrm{ADPR}$ formation (see Discussion), resulting in the $\left[\mathrm{Na}^{+}\right]_{\mathrm{i}}$ and $\left[\mathrm{Ca}^{2+}\right]_{\mathrm{i}}$ overloads.

ROS-induced mitochondrial $\mathrm{Ca}^{2+}\left(\left[\mathrm{Ca}^{2+}\right]_{\mathrm{m}}\right)$ overload is one of the major causes of myocyte apoptosis..$^{4,11,33}$ Since we found that $50 \%$ of the $\left[\mathrm{Ca}^{2+}\right]_{\mathrm{i}}$ overload originated from the

Figure $1 \mathrm{H}_{2} \mathrm{O}_{2}$ increases intracellular levels of $\mathrm{NAD}^{+}$and PAR, and 3-AB (a PARP inhibitor) partially recovers NADH levels. (A) (a-d) After addition of $100 \mu \mathrm{M} \mathrm{H} \mathrm{O}_{2}$ to the bath solution, NAD ${ }^{+}$levels increase (i.e. NADH levels decrease) rapidly and the response is reversed by addition of $10 \mu \mathrm{M}$ rotenone $(n=5)$. The basal level of $\mathrm{NAD}(\mathrm{P}) \mathrm{H}$ is normalized as $\mathrm{F} / \mathrm{F}_{0}=1$ (d). (B) Phenanthroline $\left(1 \mathrm{mM}, 30 \mathrm{~min}\right.$ pretreatment) completely inhibits the increase in $\mathrm{NAD}^{+}$levels during exposure to $\mathrm{H}_{2} \mathrm{O}_{2}$ $(n=4)$. (C) (a) 3-AB (1 mM) alone has a small, but nonsignificant, effect $\left(P>0.05,1\right.$ d) on basal NADH levels. (b, c) In the continuous presence of $\mathrm{H}_{2} \mathrm{O}_{2}$ for 60 min, there is no NADH recovery $(n=4)$, while early addition of 3-AB partially recovers the level of NADH (see text). (D) Statistical analysis of the data from (A)-(C). (E) (a) Control, (b-c) PAR immunoreactivity (see Supplementary Methods) in the nucleus ('Nu') after 20 min exposure to $20 \mu \mathrm{M}$ or $100 \mu \mathrm{M} \mathrm{H} \mathrm{H}_{2} \mathrm{O}_{2}$. (d) Time-course of changes in PAR after exposure to $100 \mu \mathrm{M} \mathrm{H}_{2} \mathrm{O}_{2}$. Note that a very low concentration of $\mathrm{H}_{2} \mathrm{O}_{2}(20 \mu \mathrm{M})$ causes an increase in PAR, while phenanthroline $(1 \mathrm{mM})$, 3-AB (1 mM), DPQ $(30 \mu \mathrm{M})$, or rotenone $(10 \mu \mathrm{M})$ markedly inhibits PAR formation at 20 min exposure. After exposure to $\mathrm{H}_{2} \mathrm{O}_{2}$ for 60 min, cells were washed ('wash' in Ed) and returned to normal medium. At least four animal preparations were used $(n=4)$, each tested in duplicate ( $\mathbf{D}$ and $\mathbf{E d})$ 

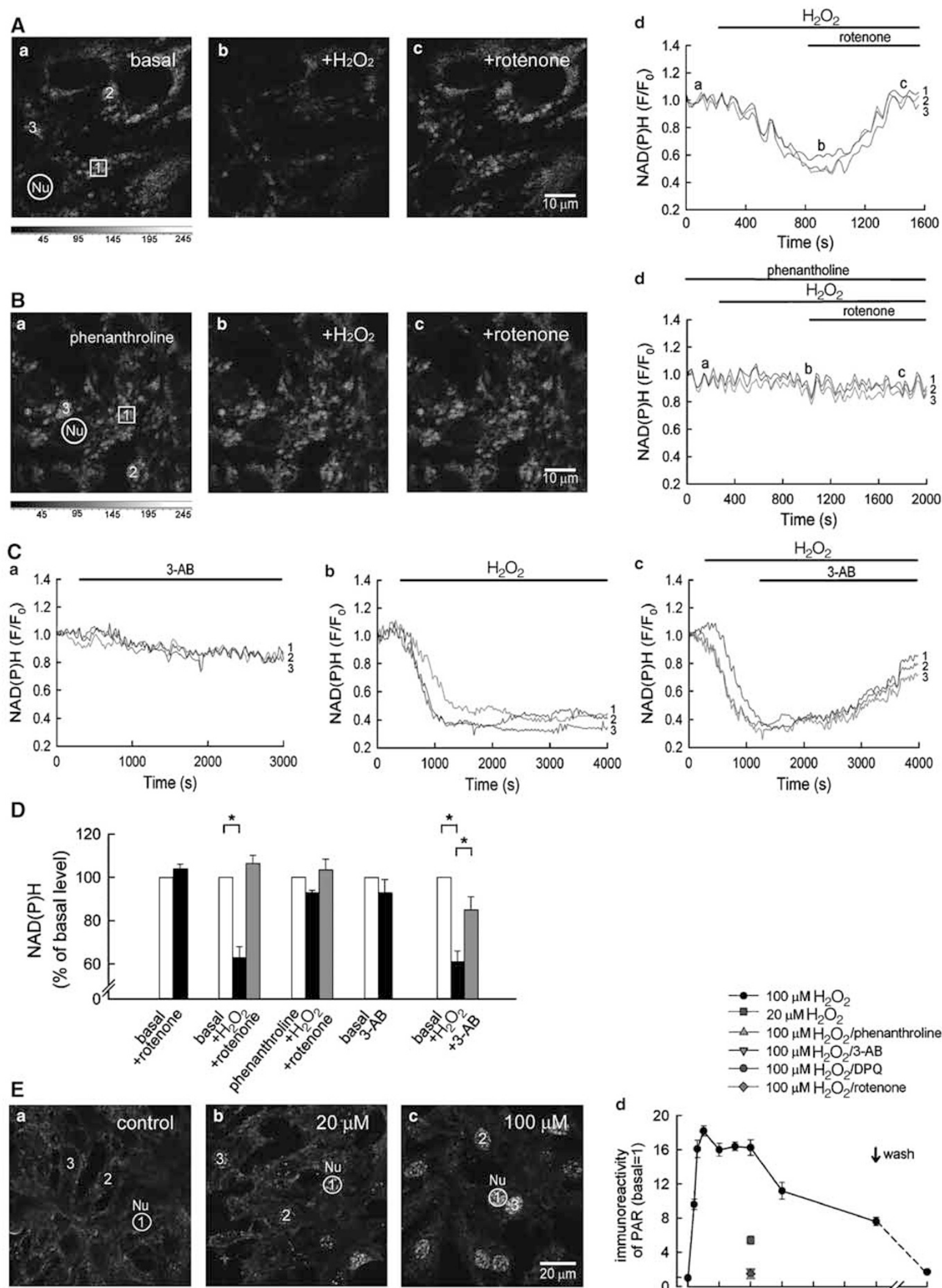

$\stackrel{\star}{\curvearrowleft}$

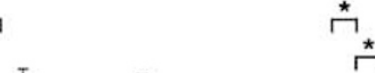

$\stackrel{\star *}{\sim^{*}}$
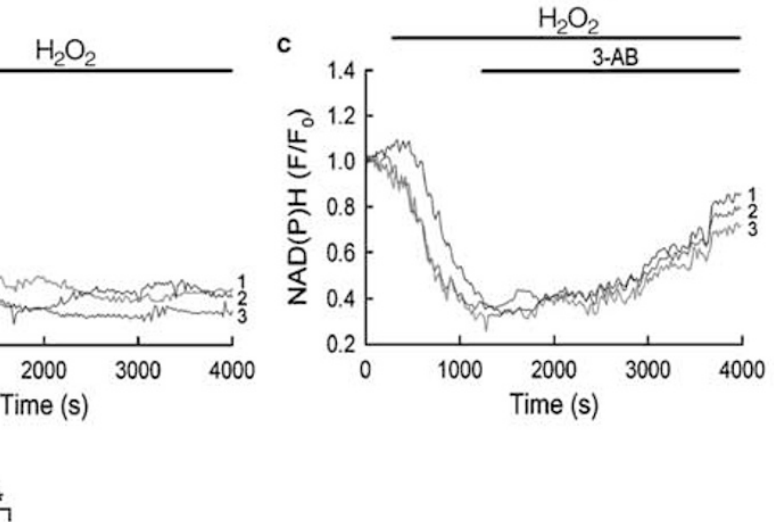

- $-100 \mu \mathrm{MH}_{2} \mathrm{O}$

$=20 \mu \mathrm{MH}_{2} \mathrm{O}_{2}$

$-\triangle-100 \mu \mathrm{MH}_{2} \mathrm{O}_{2}$ /phenanthroline

$\rightarrow-100 \mu \mathrm{MH}_{2} \mathrm{O}_{2} / 3-\mathrm{AB}$

$\rightarrow 100 \mu \mathrm{M} \mathrm{H}_{2} \mathrm{O}_{2} / \mathrm{DPQ}$

$\diamond 100 \mu \mathrm{M} \mathrm{H}_{2} \mathrm{O}_{2}$ /rotenone

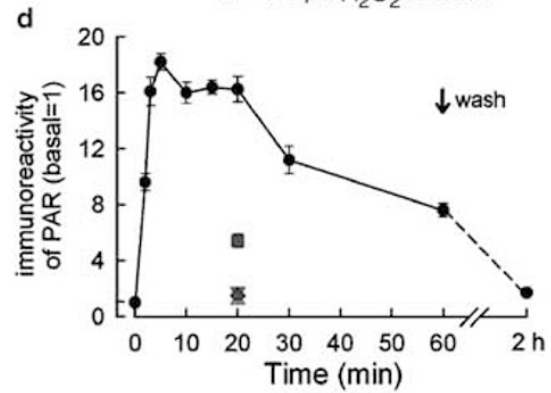


$\mathrm{H}_{2} \mathrm{O}_{2}$-induced $\left[\mathrm{Na}^{+}\right]_{i}$ overload (Supplementary Figure S3Ae$\mathrm{g}$ ), a possible role of $\left[\mathrm{Na}^{+}\right]_{\text {cyt }} /\left[\mathrm{Na}^{+}\right]_{\mathrm{m}}$ overload in myocyte death was investigated in detail.

\section{Mitochondrial $\mathrm{Na}^{+}\left(\left[\mathrm{Na}^{+}\right]_{\mathrm{m}}\right)$, but not cytosolic $\mathrm{Na}^{+}\left(\left[\mathrm{Na}^{+}\right]_{\text {cyt }}\right)$, overload is involved in the $\mathrm{H}_{2} \mathrm{O}_{2}-$ induced caspase 3-dependent apoptotic pathway}

CoroNa Red has been used to measure changes in cytosolic $\mathrm{Na}^{+}\left(\left[\mathrm{Na}^{+}\right]_{\text {cyt }}\right){ }^{34}$ Using confocal microscopy with a thin optical section $(0.04 \mu \mathrm{m})$, it can be used to simultaneously report changes in the $\left[\mathrm{Na}^{+}\right]_{\mathrm{cyt}}$ and $\left[\mathrm{Na}^{+}\right]_{\mathrm{m}}$, since only a small proportion of the probe is found in the cytosolic compartment, ${ }^{34}$ the majority being trapped by the negative mitochondrial potential because of the positive charge of the probe. Since the nuclear membrane is no barrier to cytosolic ion movement, ${ }^{35,36}$ averaging the signal over a small nuclear optical section (ER-free and mitochondria-free) or the mitochondria (identified by a mitochondrial marker, MTG, last frame in Figures $2 a$ and $\mathrm{c}$ ), respectively, allows dynamic changes in the $\left[\mathrm{Na}^{+}\right]_{\mathrm{cyt}}$ or $\left[\mathrm{Na}^{+}\right]_{\mathrm{m}}$ to be recorded.

After exposure to $100 \mu \mathrm{M} \mathrm{H}_{2} \mathrm{O}_{2}$ for $680 \mathrm{~s}$ in normal medium (Figures 2a and e, Video Supplementary Figure S1) or after clamping the $\left[\mathrm{Na}^{+}\right]_{\mathrm{i}}$ at $60 \mathrm{mM}$ using $\mathrm{Na}$-ionophore cocktail (5 $\mu \mathrm{M}$ gramicidin $\mathrm{D}, 40 \mu \mathrm{M}$ monensin, and $100 \mu \mathrm{M}$ strophanthidine) in Ca-free medium, ${ }^{33}$ the peak levels of $\left[\mathrm{Na}^{+}\right]_{\text {cyt }}$ and $\left[\mathrm{Na}^{+}\right]_{\mathrm{m}}$ were $\sim 60 \mathrm{mM}$ (Figure $2 \mathrm{e}$ ). Photobleaching of CoroNa Red did not occur, since there was little change in the absence of $\mathrm{H}_{2} \mathrm{O}_{2}$ treatment (' $-\mathrm{H}_{2} \mathrm{O}_{2}$ ' in Figure $2 \mathrm{~b}$ ). Moreover, little $\mathrm{H}_{2} \mathrm{O}_{2}$-induced $\left[\mathrm{Na}^{+}\right]_{\text {cyt }} /\left[\mathrm{Na}^{+}\right]_{m}$ increase was seen in Na-free medium, while $\mathrm{Ca}$-free medium did not have any inhibitory effect (Figure 2e), indicating that the probe is Na-sensitive and Na-selective. Pretreatment with $10 \mu \mathrm{M}$ RU360, a potent inhibitor of the mitochondrial $\mathrm{Ca}^{2+}$ import pathway, ${ }^{37,38}$ markedly inhibited the $\mathrm{H}_{2} \mathrm{O}_{2}$-/Na-ionoph-induced $\left[\mathrm{Na}^{+}\right]_{\mathrm{m}}$ overload, but not the $\left[\mathrm{Na}^{+}\right]_{\text {cyt }}$ overload (i versus ii in Figures $2 \mathrm{c}$ and $\mathrm{e})$, showing that RU360 effectively prevents $\left[\mathrm{Na}^{+}\right]_{\mathrm{m}}$ overload.

Significant chromatin condensation (arrows in Figure 2fi) and DNA fragmentation (Figure 2fii, green for TUNEL $(+)$ staining) were seen after $4.5 \mathrm{~h}$ wash-out of $\mathrm{H}_{2} \mathrm{O}_{2}$ or of $\mathrm{Na}$ ionophore cocktail/Ca-free medium (Figure $2 \mathrm{~g}$ ). Approximately $18 \%$ inhibition of condensation was seen in Ca-free medium (Figure $2 \mathrm{~g}$ ), in which the $\left[\mathrm{Ca}^{2+}\right]_{\mathrm{m}}$ overload should be totally abolished. Moreover, treatment with RU360, Na-free medium, Z-DEVD.fmk (a specific caspase 3 inhibitor), or phenanthroline (an iron chelator that prevents $\mathrm{OH}^{\bullet}$ production; Figure 6) markedly inhibited not only $\mathrm{H}_{2} \mathrm{O}_{2}$-induced, but also Na-ionophore-induced, chromatin condensation (Figure $2 \mathrm{~g}$ ), indicating that $\left[\mathrm{Na}^{+}\right]_{\mathrm{m}}$ overload per se plays an important role in caspase 3-dependent apoptosis.

Since ROS-induced $\left[\mathrm{Ca}^{2+}\right]_{i}$ overload $^{39}$ and PARP activation $^{13}$ have been suggested to also induce necrosis, we tested whether $\left[\mathrm{Ca}^{2+}\right]_{\mathrm{i}} /\left[\mathrm{Na}^{+}\right]_{\mathrm{i}}$ overload and PARP activation were involved in the necrotic machinery.

\section{PARP activation, but not $\left[\mathrm{Na}^{+}\right]_{\mathrm{i}} /\left[\mathrm{Ca}^{2+}\right]_{\mathrm{i}}$ overload per se, is involved in the $\mathrm{H}_{2} \mathrm{O}_{2}$-induced necrotic pathway}

Two common indicators used to demonstrate necrosis are membrane permeabilization and release of cytosolic protein (e.g. calcein-AM). ${ }^{12,40}$ After 60 min treatment with $100 \mu \mathrm{M}$ $\mathrm{H}_{2} \mathrm{O}_{2}$, the cells were immediately incubated with a mixture of CAM (green) and ethidium homodimer (EthD-1) (red), then washed, fixed, and stained with a muscle marker, antibody A12 (blue). In the untreated cells, the live myocytes (blue) stained green for calcein (arrows in Figure 3a) and contained no red nuclei, while $78 \pm 5 \%(n=6)$ of the $\mathrm{H}_{2} \mathrm{O}_{2}$-treated cells showed red nuclear labeling (EthD-1, arrows in Figure $3 \mathrm{~b}$ ) and no calcein staining, confirming that $\mathrm{H}_{2} \mathrm{O}_{2}$ also induces necrosis. This raises the question whether the permeabilization of the plasma membrane is due to $\left[\mathrm{Ca}^{2+}\right]_{\mathrm{i}}$ and/or $\left[\mathrm{Na}^{+}\right]_{\mathrm{i}}$ overload. To our knowledge, this possibility has not been properly tested previously. Using time-lapse confocal microscopy of live myocytes, the temporal profiles of changes in the $\left[\mathrm{Ca}^{2+}\right]_{\mathrm{i}}$ (fluo 3-loaded cells) and membrane permeabilization (propidium iodide (PI) added to the external medium) were measured simultaneously.

When myocytes were treated with $\mathrm{H}_{2} \mathrm{O}_{2}$, a slow increase in the $\left[\mathrm{Ca}^{2+}\right]_{i}$ was seen (green, Figure $3 \mathrm{c}$ ). Extracellular $\mathrm{PI}$ did not enter the cell and stain the nuclei (red) until the fluo 3 had started to leak out slowly (Figure 3c, see video Supplementary Figure S2), indicating that the early $\mathrm{Ca}^{2+}$ influx (and $\mathrm{Na}^{+}$ influx, not shown) was not due to membrane permeabilization. Moreover, the $\mathrm{Ca}^{2+}$ influx was completely inhibited by phenanthroline (an $\mathrm{OH}^{\bullet}$ inhibitor, Figures 3e and 6) but partially inhibited by DPQ (a PARP inhibitor) (Figure 3f). Importantly, the permeabilization was independent of $\left[\mathrm{Na}^{+}\right]_{\mathrm{i}}$ or $\left[\mathrm{Ca}^{2+}\right]_{\mathrm{i}}$ overload, since Ca-free (Figure $3 \mathrm{~g}$ ) or $\mathrm{Na}-\mathrm{Ca}$-free medium (Figure $3 d$ ) did not inhibit the PI influx.

The level of the $[A T P]_{i}$ has been suggested to be the switch deciding between apoptosis and necrosis, since the formation of the apoptosome in the caspase 3-mediated apoptotic pathway is dATP/ATP-dependent (Figure 6). ${ }^{12}$ Since $\mathrm{H}_{2} \mathrm{O}_{2}$ induced both membrane permeabilization (Figure $3 \mathrm{~b}$ and $\mathrm{c}$ )

Figure $2\left[\mathrm{Na}^{+}\right]_{\mathrm{m}}$ overload per se initiates caspase 3-dependent apoptosis. $(\mathbf{a}, \mathbf{b}) \mathrm{H}_{2} \mathrm{O}_{2}$ induces both $\left[\mathrm{Na}^{+}\right]_{\mathrm{cyt}}$ ('Nu', nucleus) and mitochondrial (Mt) $\mathrm{Na}^{+}\left(\left[\mathrm{Na}{ }^{+}\right]_{\mathrm{m}}\right)$ overload. See Supplementary Methods for measurement and transformation into $\left[\mathrm{Na}^{+}\right]_{\text {cyt }} /\left[\mathrm{Na}^{+}\right]_{\mathrm{m}}($ in $\mathrm{mM})$. (c-e) Na-ionophore cocktail medium ('Na-ionoph') also induces $\left[\mathrm{Na}^{+}\right]_{\text {cyy }} /\left[\mathrm{Na}^{+}\right]_{\mathrm{m}}$ overload (e) and RU360 selectively inhibits the $\mathrm{H}_{2} \mathrm{O}_{2}-/ \mathrm{Na}^{+}$ionoph-induced $\left[\mathrm{Na}^{+}\right]_{\mathrm{m}}$ overload (i versus ii in c), but not the $\left[\mathrm{Na}^{+}\right]_{\text {cyt }}$ overload $(\mathbf{d}$ e). The $\mathrm{Na}^{+}$ionophore cocktail medium effectively clamps the $\left[\mathrm{Na}^{+}\right]_{\mathrm{i}}=\left[\mathrm{Na}^{+}\right]_{0} \cdot{ }^{33}$ The Na-ionoph/Ca-free medium contained $5 \mu \mathrm{M}$ gramicidin D, $40 \mu \mathrm{M} \mathrm{monensin,} \mathrm{and}$ $100 \mu \mathrm{M}$ strophanthidine in $60 \mathrm{mM} \mathrm{NaCl}$-containing medium. Note that the Ca-free medium has little inhibitory effect on the $\mathrm{H}_{2} \mathrm{O}_{2}$-induced $\left.\mathrm{Na}^{+}\right]_{\mathrm{cy}} /\left[\mathrm{Na}^{+}\right]_{\mathrm{m}}$ overload $(\mathbf{e})$. (f) Cells were exposed to $100 \mu \mathrm{M} \mathrm{H}_{2} \mathrm{O}_{2}$ for $60 \mathrm{~min}$, then returned to normal medium for $4.5 \mathrm{~h}$; the nucleus shows chromatin condensation (arrows in $\mathrm{i}$, Hoechst staining) and DNA fragmentation (ii) (green or blue for TUNEL or myocyte staining, respectively; see Supplementary Methods). (g) Prevention of [Na $\left.{ }^{+}\right]_{\mathrm{m}}$ overload by RU360 inhibits the caspase 3-dependent apoptosis. In Ca-free medium, there is an $\sim 18 \%$ inhibition of the nuclear condensation. The Na-ionoph/Ca-free medium was exposed for $30 \mathrm{~min}$ and wash-out for $4.5 \mathrm{~h} . \mathrm{H}_{2} \mathrm{O}_{2}(100 \mu \mathrm{M})$, Z-DEVD.fmk ( $100 \mu \mathrm{M}, 2 \mathrm{~h}$ pretreatment, a caspase 3 inhibitor), phenanthroline (1 mM, 30 min pretreatment), and RU360 (10 $\mu \mathrm{M}, 2 \mathrm{~h}$ pretreatment) were used. All results are expressed as the mean \pm S.E.M. for at least four animal preparations $(n=4)$, each tested in duplicate. In all, 200 cells from 10 randomly selected fields were scored on each coverslip. ${ }^{*} P<0.05$ compared, respectively, to the $\mathrm{H}_{2} \mathrm{O}_{2}$ group or Na-ionoph group as appropriate 

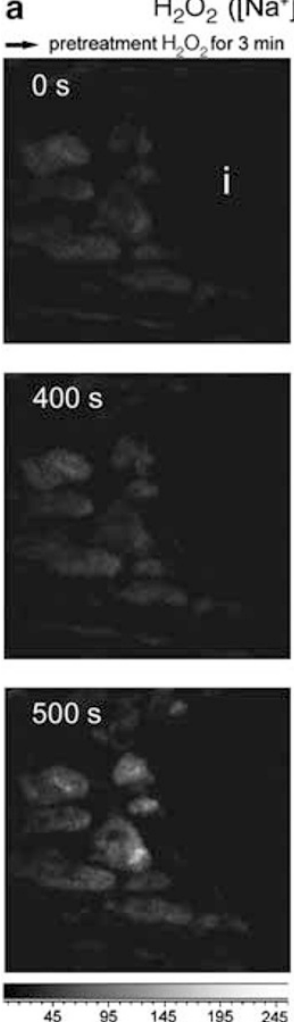

b

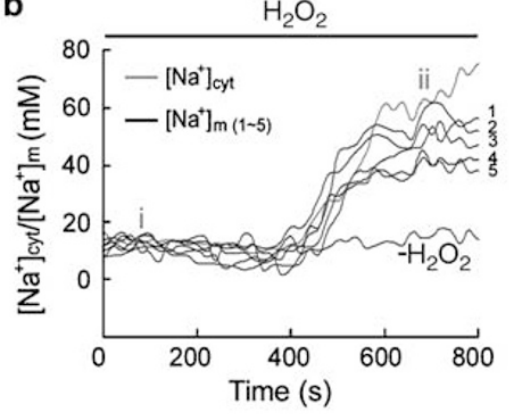

e

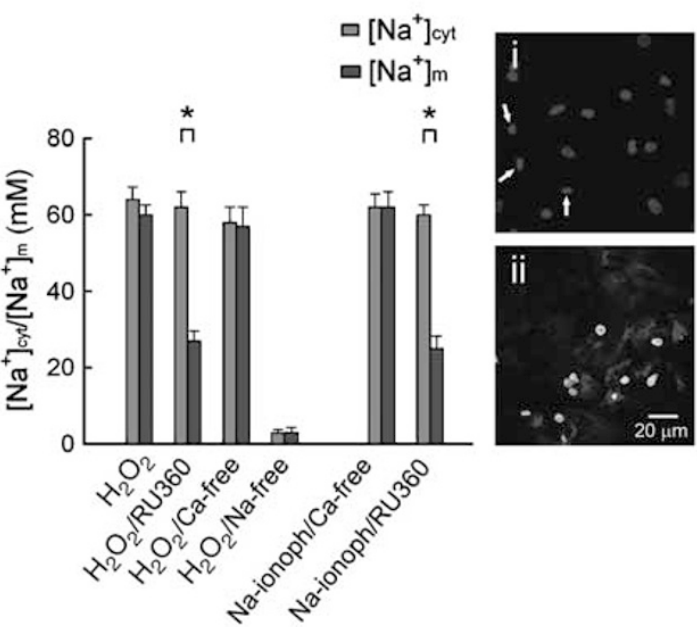

C Na-ionoph/RU360 ([Na+ $\left.]_{\text {cyl }} /\left[\mathrm{Na}^{+}\right]_{\mathrm{m}}\right)$
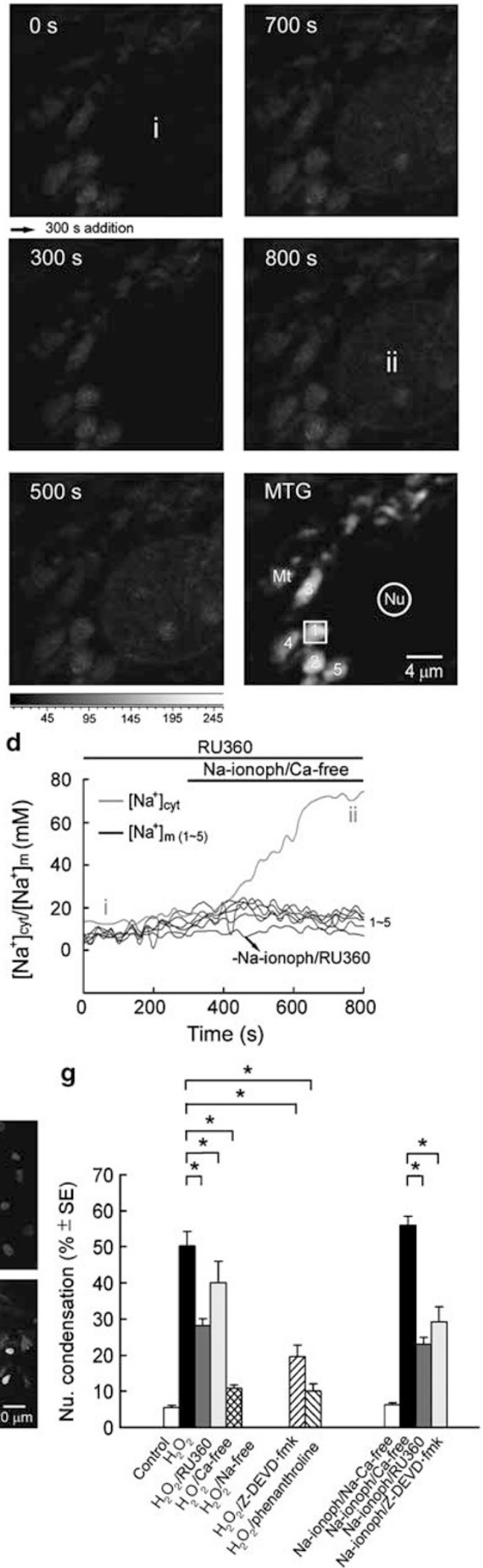
a
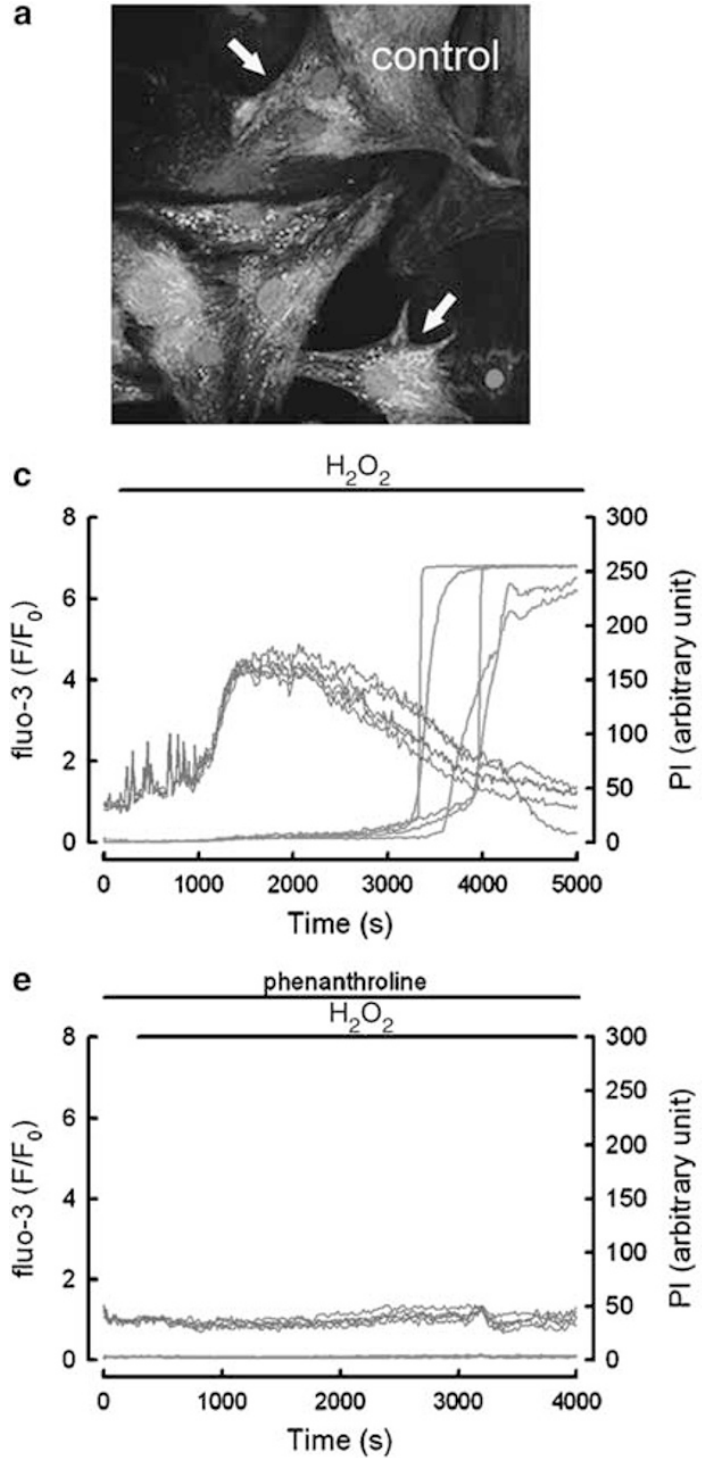

g

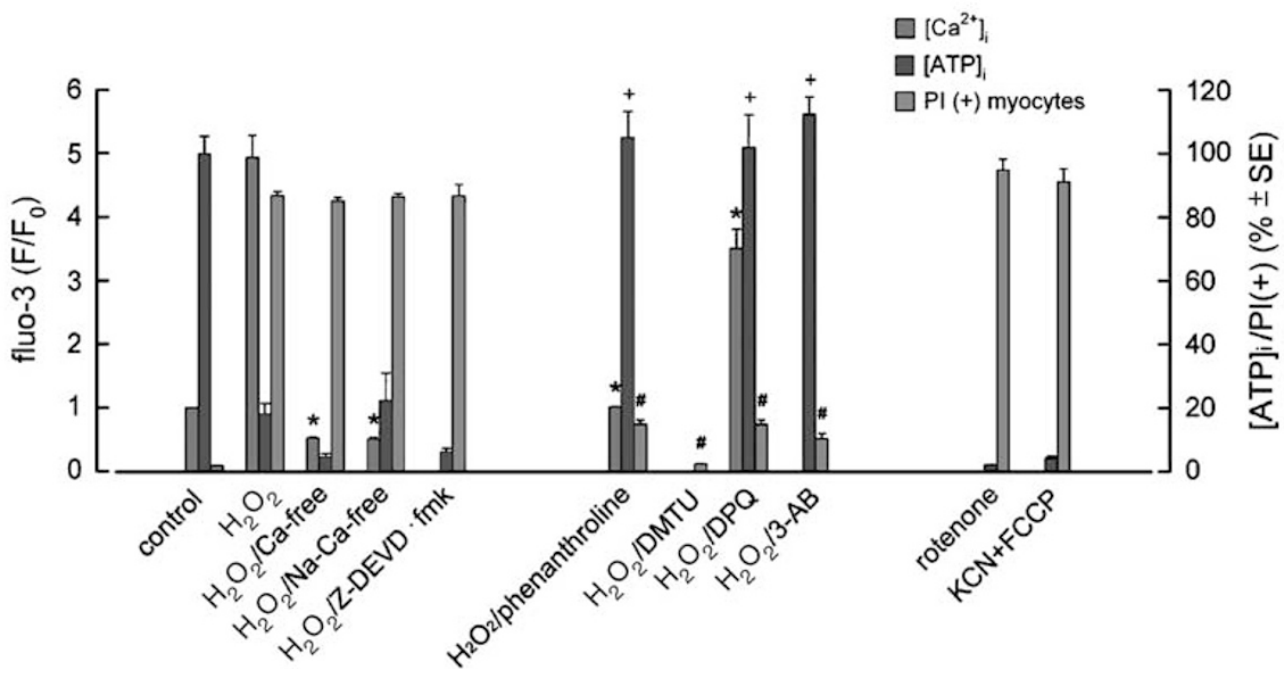

b
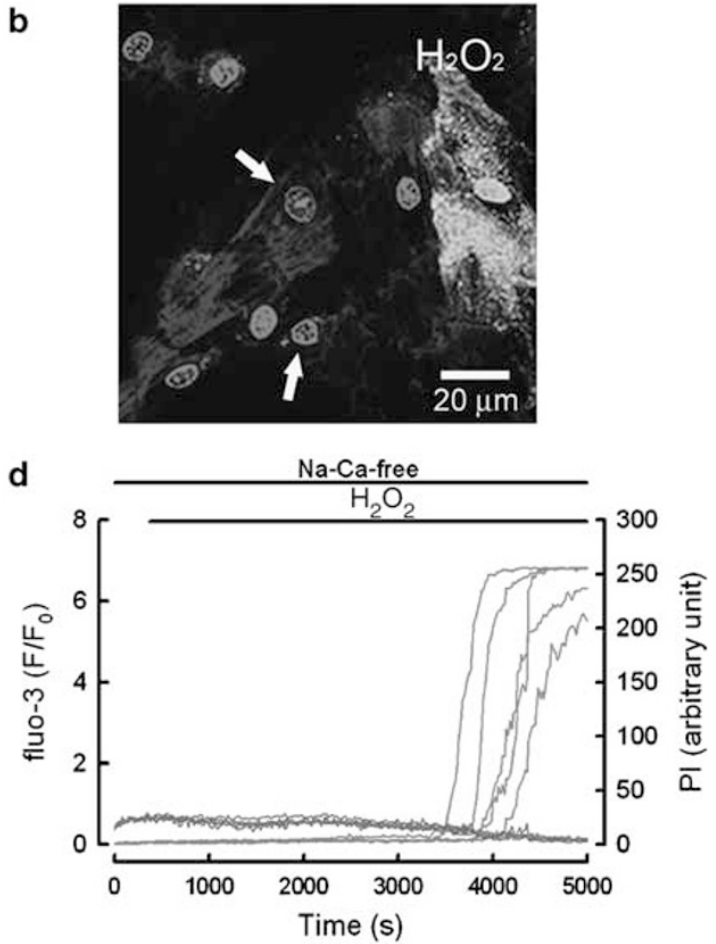

f

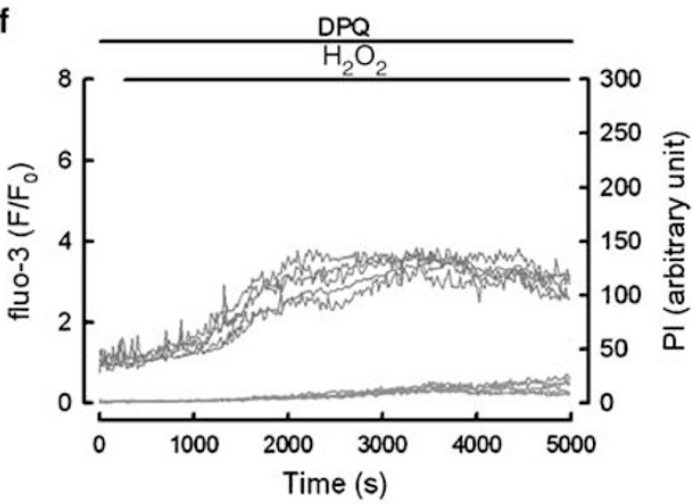

$\square\left[\mathrm{Ca}^{2+}\right]_{i}$

$\square$ [ATP]

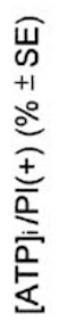


and caspase 3-dependent nuclear condensation (Figure 2g), the $[\text { ATP }]_{i}$ was measured. After 60 min treatment with $100 \mu \mathrm{M}$ $\mathrm{H}_{2} \mathrm{O}_{2}$ in normal medium, Ca-free medium, or $\mathrm{Na}-\mathrm{Ca}$-free medium, or with chemical ischemia (rotenone or KCN/FCCP), the $[A T P]_{i}$ markedly decreased and PI staining increased (Figure 3g). Inhibition of $\mathrm{OH}^{\bullet}$ production (phenanthroline or DMTU) or of PARP activation (DPQ or 3-AB) prevented the $\mathrm{H}_{2} \mathrm{O}_{2}$-induced [ATP $]_{i}$ depletion and increase in PI staining (i.e. membrane permeabilization; Figure $3 \mathrm{~g}$ ). Importantly, the membrane permeabilization and $[A T P]_{i}$ depletion were not inhibited by a specific caspase 3 inhibitor, Z-DEVD.fmk (Figure $3 \mathrm{~g}$ ), suggesting that $\mathrm{OH}^{\bullet}$ induced PARP activation (Figure 6), via a caspase 3-independent necrotic pathway.

We next investigated the molecular mechanisms for the caspase 3-dependent and caspase 3-independent cell death.

\section{Mechanisms for activation of both apoptotic and necrotic machineries in a single myocyte}

$\mathrm{H}_{2} \mathrm{O}_{2}$-induced $\mathrm{Na}^{+}$or $\mathrm{Ca}^{2+}$ influx was monitored by recording changes in the $\left[\mathrm{Na}^{+}\right]_{i}$ (using SBFI-AM) or $\left[\mathrm{Ca}^{2+}\right]_{i}$ (using fura 2-AM) (Supplementary Methods). When cells were exposed to $20-500 \mu \mathrm{M} \mathrm{H}_{2} \mathrm{O}_{2}$ for 20-25 min, there was a parallel increase in the $\left[\mathrm{Na}^{+}\right]_{i}$ and $\left[\mathrm{Ca}^{2+}\right]_{i}$ (Figure 4a). Since a smaller inhibitory effect on nuclear condensation was seen under $\mathrm{Ca}$-free conditions than under $\mathrm{Na}$-free conditions (Figure 2g), Na-free medium was used when different concentrations of $\mathrm{H}_{2} \mathrm{O}_{2}(20-500 \mu \mathrm{M})$ were applied (brown line in Figure 4b). We found that, even at a low $\mathrm{H}_{2} \mathrm{O}_{2}$ concentration $(20 \mu \mathrm{M})$, inhibition of $\left[\mathrm{Na}^{+}\right]_{\mathrm{i}} /\left[\mathrm{Na}^{+}\right]_{\mathrm{m}}$ overload largely inhibited condensation (measured at $4.5 \mathrm{~h}$ wash-out, brown versus black in Figure $4 \mathrm{~b}$ ). Moreover, an increase in the $\mathrm{H}_{2} \mathrm{O}_{2}$ concentration (20-500 $\mu \mathrm{M} \mathrm{H}_{2} \mathrm{O}_{2}$ exposure for 60 min) resulted in a decrease in the $[A T P]_{i}$ and an increase in membrane permeability $\mathrm{PI}(+)$ staining (Figure $4 \mathrm{~b})$.

A constant concentration of $100 \mu \mathrm{M} \mathrm{H}_{2} \mathrm{O}_{2}$ was then used to explore the temporal relationship between $[A T P]_{i}$ depletion, membrane permeabilization, caspase 3 activation, and nuclear condensation. After $40 \mathrm{~min}$ of $\mathrm{H}_{2} \mathrm{O}_{2}$ exposure, the $[A T P]_{i}$ was reduced to $\sim 20 \%$ of control levels (blue, Figure $4 \mathrm{c}$ ) and this was followed by a rapid increase in PI staining (red) at $60 \mathrm{~min}$ (Figures $3 \mathrm{c}$ and 4c; see video Supplementary Figure S2), indicating that depletion of [ATP $]_{1}$ may increase the membrane permeability, as suggested by other studies. $^{12,13}$ However, marked caspase 3 activation (green) was already seen at 20 min (Figure 4c), that is, earlier than $[A T P]_{i}$ depletion and $\mathrm{PI}$ influx. Chromatin condensation was not seen until after $2 \mathrm{~h}$ of wash-out of $\mathrm{H}_{2} \mathrm{O}_{2}$ (arrows, Figure $4 \mathrm{ci}$ ), then increased with time. Furthermore, all a

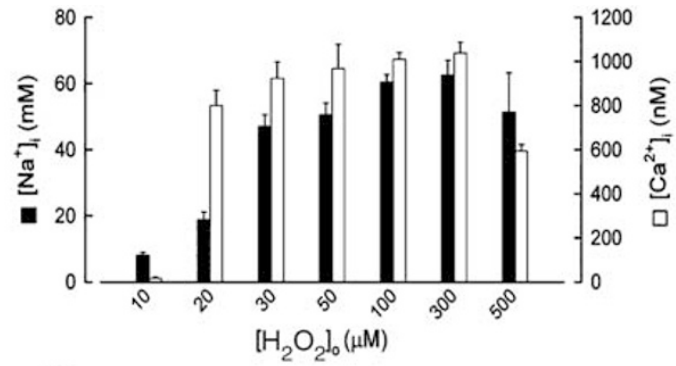

b

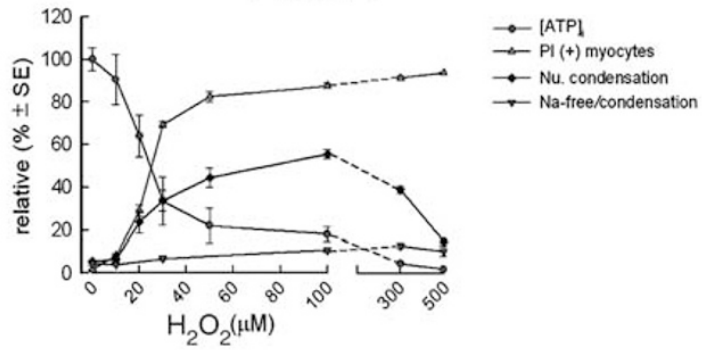

C $\rightarrow$ ATPS $\rightarrow \mathrm{Pl}(+) \operatorname{moc}(0)$ $\rightarrow$ caspase 3 $\rightarrow-\mathrm{Nu}$ condensation $(+\mathrm{YPI}(+)$ $\rightarrow$ Z-DEVD - fmktcondensation
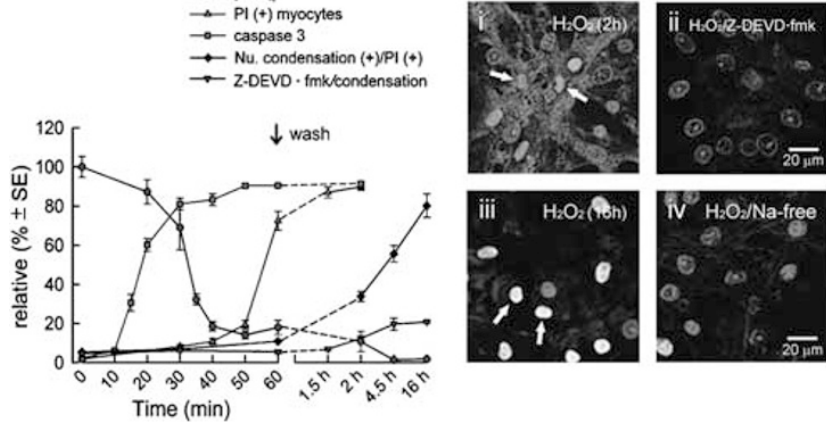

Figure $4 \quad \mathrm{H}_{2} \mathrm{O}_{2}$ evokes two modes of cell death in the same myocyte via caspase 3independent membrane permeabilization and $\mathrm{Na}$-sensitive, caspase 3-dependent nuclear changes. (a) Dose-response for the peak level of the $\mathrm{H}_{2} \mathrm{O}_{2}$-induced [ $\left.\mathrm{Na}^{+}\right] / /$

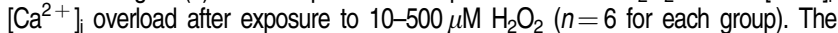
$\left[\mathrm{Na}^{+}\right]_{i}$ or $\left[\mathrm{Ca}^{2+}\right]_{i}$ were measured by SBFI-AM or fura 2-AM, respectively (see Supplementary Methods). (b) Changes in [ATP] (see Supplementary Methods), membrane permeability (PI staining), nuclear condensation after 60 min exposure to $10-500 \mu \mathrm{M} \mathrm{H}_{2} \mathrm{O}_{2}(n=5)$. [ATP] and PI staining were immediately measured after $\mathrm{H}_{2} \mathrm{O}_{2}$ treatment. Na-sensitive nuclear condensation (black versus brown, Hoechst staining) was measured after $4.5 \mathrm{~h}$ wash-out of $10-500 \mu \mathrm{M} \mathrm{H} \mathrm{H}_{2}$ (exposure for $60 \mathrm{~min}$ ). (c) Time-course of changes in [ATP], (blue), PI staining (red), caspase 3 activation (green), and Z-DEVD.fmk (brown)-sensitive chromatin condensation after exposure to $100 \mu \mathrm{M} \mathrm{H}_{2} \mathrm{O}_{2}$. Cells were exposed to $100 \mu \mathrm{M} \mathrm{H}_{2} \mathrm{O}_{2}$ for 60 min, followed by wash-out (red arrow) for 1.5-16 h. The black line in (c) is the myocyte, which is stained positively for both nuclear condensation and PI within one cell. (c) (i) Caspase 3 activation (green), nuclear condensation (arrows), and membrane permeabilization (red) are seen in the same myocyte after $2 \mathrm{~h}$ wash-out of $\mathrm{H}_{2} \mathrm{O}_{2}$. (ii) Caspase 3 activation and nuclear condensation, but not membrane permeabilization, are markedly inhibited by $100 \mu \mathrm{M}$ Z-DEVD.fmk. (iii) After 60 min treatment with $\mathrm{H}_{2} \mathrm{O}_{2}$, followed by $16 \mathrm{~h}$ wash-out, myocytes show double labeling (yellow) for TUNEL (green, DNA fragmentation) and $\mathrm{PI}$ (red). (iv) Na-free medium markedly inhibits $\mathrm{H}_{2} \mathrm{O}_{2}$-induced DNA fragmentation, but not membrane permeabilization, indicating an antiapoptotic effect at least for $16 \mathrm{~h}$ using Na-free medium (see Supplementary Methods for staining)

Figure 3 PARP activation is involved in the $\mathrm{H}_{2} \mathrm{O}_{2}$-induced [ATP] $]_{i}$ depletion and membrane permeabilization, which are both caspase 3-independent. (a) Controls (arrows). (b) The membrane permeability increases after 60 min exposure to $100 \mu \mathrm{M} \mathrm{H}_{2} \mathrm{O}_{2}$. Membrane permeabilization (EthD-1 ( + ) staining) is shown by the arrows, stained with calcein (green), EthD-1 (red), and antibody A12 (blue). (c-f) Time-lapse recordings of $\mathrm{H}_{2} \mathrm{O}_{2}$-induced $\mathrm{Ca}^{2+}$ influx (measured by fluo 3 AM, see Supplementary Methods), followed by PI influx (membrane permeabilization) in live myocytes ( $n=4$, see also video Supplementary Figure S2). Phenanthroline (1 mM) completely, and DPQ $(30 \mu \mathrm{M})$ partially, inhibits the $\mathrm{Ca}^{2+}$ influx (both $\left.n=4\right)$. (g) Summary histograms for the peak [Ca $\left.{ }^{2+}\right]_{i}$ response (green, data from c-f) and [ATP] (blue) and PI staining (red) after various treatments. Ca-, Na-Ca-free, or Z-DEVD.fmk (100 $\mu \mathrm{M}$, a caspase 3 inhibitor) has little inhibitory effect on [ATP] depletion and membrane permeabilization, while PARP inhibitors ( $1 \mathrm{mM} 3-\mathrm{AB}$ and $30 \mu \mathrm{M} \mathrm{DPQ}$ ) or $\mathrm{OH}^{\bullet}$ scavengers ( $1 \mathrm{mM}$ phenanthroline and $20 \mathrm{mM}$ DMTU) abolish both effects. The concentrations of rotenone, $\mathrm{KCN}$, or FCCP were $10 \mu \mathrm{M}, 5 \mathrm{mM}$, or $1 \mu \mathrm{M}$, respectively. [ATP] $]_{i}$ and PI staining were measured immediately after 60 min treatment. All results are expressed as the mean + S.E.M. for at least five animal preparations $(n=5)$, each tested in duplicate. ${ }^{*+\# ~} P<0.05$, compared to the $\mathrm{H}_{2} \mathrm{O}_{2}$-induced $\left[\mathrm{Ca}^{2+}\right]_{\mathrm{i}}$ increase $\left({ }^{*}\right),[\mathrm{ATP}]_{\mathrm{i}}$ depletion $\left({ }^{+}\right)$, and membrane permeabilization $\left(\mathrm{PI}(+),{ }^{\#}\right)$ as appropriate 
condensed nucleus (Hoechst staining) was also stained by $\mathrm{PI}$ (black, Figure 4c). After $16 \mathrm{~h}$ of wash-out, for example, the same nucleus in $80 \%$ of myocytes was stained with both TUNEL (DNA fragmentation) and PI (yellow, Figure 4ciii). Again, Na-free medium largely prevented TUNEL staining (yellow; Figure 4civ), but not PI staining (red), confirming that the membrane permeabilization seen in Figure $3 \mathrm{~g}$ was $\left[\mathrm{Na}^{+}\right]_{i-}$ independent. Importantly, caspase 3 activation (green), chromatin condensation (arrows), and PI staining (red) were all seen within the same myocyte (Figure 4ci), indicating that both modes of cell death were induced by $\mathrm{H}_{2} \mathrm{O}_{2}$ in the same cell. Z-DEVD.fmk did not inhibit PI staining (Figure 4cii), but abolished both caspase 3 activation (Figure 4ci versus cii) and chromatin condensation (brown line in Figure 4c), indicating that the nuclear condensation, but not the membrane permeabilization, was caspase 3-dependent.

These results show that both TRPM2-induced $\left[\mathrm{Na}^{+}\right]_{\mathrm{m}}$ (and $\left[\mathrm{Ca}^{2+}\right]_{\mathrm{m}}$ ) overload and PARP-dependent $[\text { ATP }]_{\mathrm{i}}$ depletion are important in the induction of the untypical cell death (Figure 6). We next tested whether the simultaneous inactivation of both the TRPM2 and PARP conferred a better protective effect.

\section{Inhibition of both TRPM2 opening and PARP activation prevents both modes of cell death}

Since both $\mathrm{NAD}^{+}$and ADPR are suggested to be specific messengers for TRPM2 opening, we manipulated endogenous levels of $\mathrm{NAD}^{+}$and/or ADPR or directly inhibited the TRPM2, then examined (i) whether NAD ${ }^{+}$and/or ADPR were involved in the $\mathrm{H}_{2} \mathrm{O}_{2}$-/TRPM2-induced $\mathrm{Na}^{+} / \mathrm{Ca}^{2+}$ influx, and (ii) whether simultaneous inhibition of both TRPM2 and PARP activity prevented both modes of cell death.

Phenanthroline or rotenone, which inhibited the increase in levels of both $\mathrm{NAD}^{+}$and PAR/ADPR (Figures 1B, E, and 6), or clotrimazole, a putative TRPM2 inhibitor (Supplementary Figure $\mathrm{S} 2 \mathrm{Ab}$ ), completely inhibited the $\mathrm{H}_{2} \mathrm{O}_{2}$-induced $\mathrm{Na}^{+}$ influx (Figure 5A and $\mathrm{C}$ ) and $\mathrm{Ca}^{2+}$ influx (not shown), resulting in rapid recovery from $\left[\mathrm{Na}^{+}\right]_{i}$ overload in the absence of an $\mathrm{Na}-\mathrm{K}$ ATPase inhibitor. However, 3-AB/DPQ, which completely inhibited the increase in PAR/ADPR levels (Figure 1Ed) while partially restoring NADH/NAD ${ }^{+}$levels (Figure $1 \mathrm{Cc}$ ), had a small inhibitory effect on both the $\left[\mathrm{Ca}^{2+}\right]_{\mathrm{i}}$ overload (Figures $3 f$ and $5 \mathrm{~B})$ and the $\left[\mathrm{Na}^{+}\right]_{i}$ overload $(33 \pm 5 \%$ for $3-\mathrm{AB}, n=4)$, indicating that both $\mathrm{NAD}^{+}$and $\mathrm{ADPR}$ are involved in the
TRPM2 opening. Thus, PARP activation contributes not only to membrane permeabilization but also to TRPM2 opening.

Direct inhibition of TRPM2 by clotrimazole did not inhibit the $\mathrm{H}_{2} \mathrm{O}_{2}$-induced membrane permeabilization (red bar in Figure 5Giii), but almost completely abolished cytC release (Figure 5D), caspase 3 activation (green fluorescence in Figure 5Ei; Figure 5Eii: red for myocyte marker), and nuclear condensation/fragmentation (Figure $5 \mathrm{~F}$ and green bar in Figure 5Giii), indicating that TRPM2 activation is involved in the apoptotic process. Z-DEVD.fmk markedly abolished the nuclear condensation (Figure $2 \mathrm{~g}$ ) and TUNEL response (green bars in Figure 5Giii), but not the EthD-1 staining (red bar in Figure 5Giii), again suggesting that DNA fragmentation/ condensation, but not membrane permeabilization, is caspase 3-dependent. In contrast, inhibition of PARP activity by 3-AB or DPQ completely abolished membrane permeabilization (red bars in Figure 5Giii), but only had a weak inhibitory effect on condensation/fragmentation (15-20\%; Figure 5F and Giii). These results therefore suggest that both TRPM2 opening and PARP activation are involved in the cell death. Simultaneous inhibition of TRPM2 and PARP almost completely abolished both the apoptotic (TUNEL staining) and necrotic features (EthD-1 staining, blue for myocyte marker in Figure 5Gii and Giii).

When examined by EM, myocytes exposed to $100 \mu \mathrm{M} \mathrm{H}_{2} \mathrm{O}_{2}$ for $60 \mathrm{~min}$ (Figure $5 \mathrm{Hb}$ ) showed disruption of membrane integrity (arrows) and mitochondrial hernia and loss of cristae (arrow heads). Little change in chromatin was seen after 60 min exposure to $\mathrm{H}_{2} \mathrm{O}_{2}$ (Figure $5 \mathrm{Hb}$, see the red nucleus in Figure $3 \mathrm{~b}$ ), but chromatin fragmentation was more obvious after $4.5 \mathrm{~h}$ (inset, see TUNEL staining in Figure 2fii). These ultrastructure changes were very similar to those seen in the infarct/peri-infarct zone in I/R animal studies. ${ }^{16-18}$

It has been suggested that PTP opening induces water influx, resulting in disruption of the outer mitochondrial membrane (OMM, i.e. hernia), followed by cytC release. ${ }^{4,10}$ The present study showed that the use of Na-free medium largely prevented $\mathrm{H}_{2} \mathrm{O}_{2}$-induced mitochondrial hernia formation and loss of cristae (arrow heads, Figure $5 \mathrm{Hc}$ ), but did not protect the plasma membrane (arrows), suggesting that the $\mathrm{H}_{2} \mathrm{O}_{2}$-/TRPM2-induced [ $\left.\mathrm{Na}^{+}\right]_{\mathrm{m}}$ overload (Figures $2 \mathrm{a}, 5 \mathrm{~A}$ and C) was important in $\mathrm{OMM}$ disruption and clotrimazolesensitive cytC release (Figure 5D). Cotreatment with 3-AB (PARP inhibition) and clotrimazole (inhibition of both $\mathrm{Na}^{+}$/ $\mathrm{Ca}^{2+}$ influx) markedly prevented the mitochondrial swelling,

Figure 5 Inhibition of both TRPM2 opening and PARP activation prevents both apoptotic and necrotic features. (A, C). In the absence of an Na-K ATPase inhibitor, $1 \mathrm{mM}$ phenanthroline (30 min pretreatment, $n=4)$, rotenone $(10 \mu \mathrm{M}, n=5)$, or clotrimazole $(50 \mu \mathrm{M}, n=5)$ completely abolishes $\mathrm{H}_{2} \mathrm{O}_{2}(100 \mu \mathrm{M})$-induced Na ${ }^{+}$influx and accelerates recovery from $\left[\mathrm{Na}^{+}\right]_{\mathrm{i}}$ overload. (B) Pretreatment with PARP inhibitors, $3-\mathrm{AB}(1 \mathrm{mM})$, or $\mathrm{DPQ}(30 \mu \mathrm{M})$, partially inhibits the $\left[\mathrm{Ca}^{2+}\right]_{\mathrm{i}}$ overload $-33 \pm 5 \%$ for $3-A B, 27 \pm 5 \%$ for DPQ, both $n=5$. (D, E) The $\mathrm{H}_{2} \mathrm{O}_{2}$-induced cytC release (D) and caspase 3 activation (green fluorescence, Ei) are completely inhibited by $50 \mu \mathrm{M}$ clotrimazole $(n=5)$, a putative TRPM2 inhibitor. CytC release and caspase 3 activation were measured immediately after $100 \mu \mathrm{M} \mathrm{H} \mathrm{H}_{2} \mathrm{O}_{2}$ exposure for 60 min. $(\mathbf{F})$ Clotrimazole almost completely inhibits nuclear condensation $(n=5)$, while 3-AB or DPQ inhibits condensation by $\sim 15-20 \%$ ( $n=4)$. (G) (i, ii) Myocytes (blue) staining with both TUNEL (green, DNA fragmentation) and EthD-1 (red, membrane permeabilization) are shown with yellow nuclei and was abolished by cotreatment with clotrimazole and DPQ. (iii) After simultaneous inhibition of both TRPM2 and PARP activity by cotreatment with clotrimazole $(n=5)$ and DPQ $(n=4)$ or $3-\mathrm{AB}(n=6)$, $\mathrm{H}_{2} \mathrm{O}_{2}$-induced DNA fragmentation (TUNEL, green) and membrane permeabilization (EthD-1, red) are markedly inhibited. Note that Z-DEVD.fmk (100 $\mu \mathrm{M}$ ) inhibits the TUNEL response, but not membrane permeabilization $(n=5)$. Nuclear condensation and fragmentation were measured after $4.5 \mathrm{~h}(\mathbf{F}, \mathbf{G})$ wash-out of $\mathrm{H}_{2} \mathrm{O}_{2}$. $(\mathbf{H})$ Electron micrographs. (a) control, (b) an increase in plasma membrane permeability (black arrows) and mitochondrial (Mt) hernia and loss of cristae (arrow heads) are seen after $60 \mathrm{~min}$ exposure to $100 \mu \mathrm{M} \mathrm{H}_{2} \mathrm{O}_{2}$. Inset: chromatin condensation/fragmentation is more obvious at $4.5 \mathrm{~h}$. (c) Na-free medium prevents the hernia (i.e. breakdown of the OMM, arrow heads) without preventing the mitochondrial swelling or protecting the plasma membrane (arrows). (d) Cotreatment with 3-AB and clotrimazole markedly prevents membrane permeabilization (arrows), OMM rupture (arrow heads), and chromatin fragmentation (measured at $4.5 \mathrm{~h}$ after wash-out of $\left.\mathrm{H}_{2} \mathrm{O}_{2}\right)$ 
OMM disruption (arrow heads), plasma membrane permeabilization (arrows in Figure $5 \mathrm{Hb}$ ), and chromatin fragmentation normally seen after $4.5 \mathrm{~h}$ exposure to $\mathrm{H}_{2} \mathrm{O}_{2}$ (inset, Figures $2 \mathrm{fi}$ and $5 \mathrm{Hb}$ ), again showing that activation of both TRPM2 and
PARP was involved in the generation of the mixed features of cell death (Figure 6). However, mitochondrial swelling was not abolished in $\mathrm{H}_{2} \mathrm{O}_{2} / \mathrm{Na}$-free medium (Figure $5 \mathrm{Hc}$ ), possibly because a $\left[\mathrm{Ca}^{2+}\right]_{\mathrm{i}}$ overload $(\sim 500 \mathrm{nM}, \sim 50 \%$ inhibition by
A

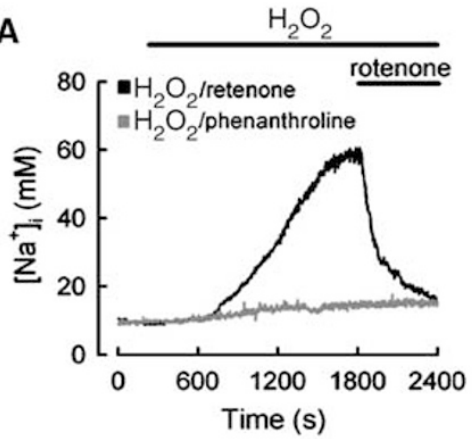

D

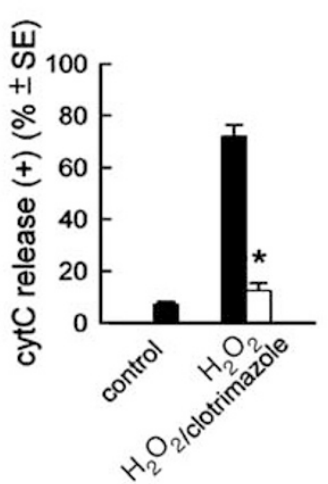

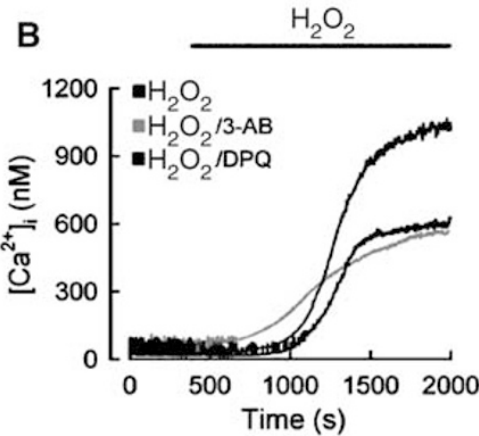

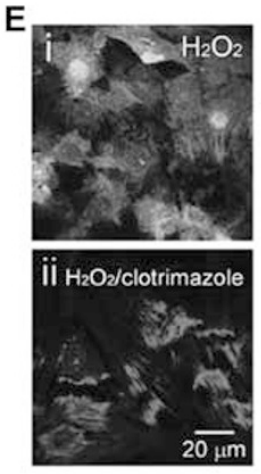

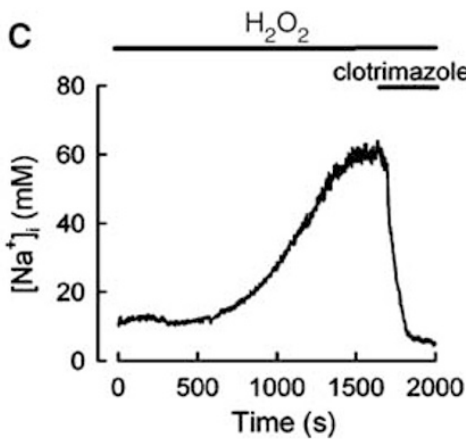

$\mathrm{F}$
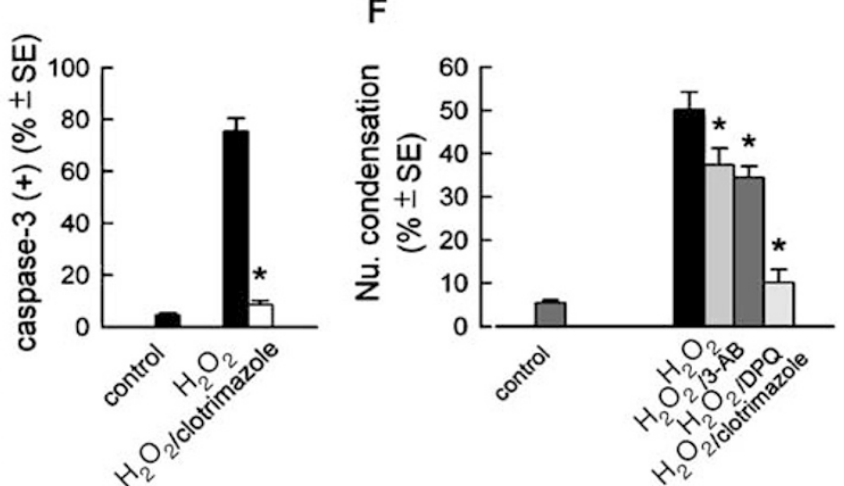

G
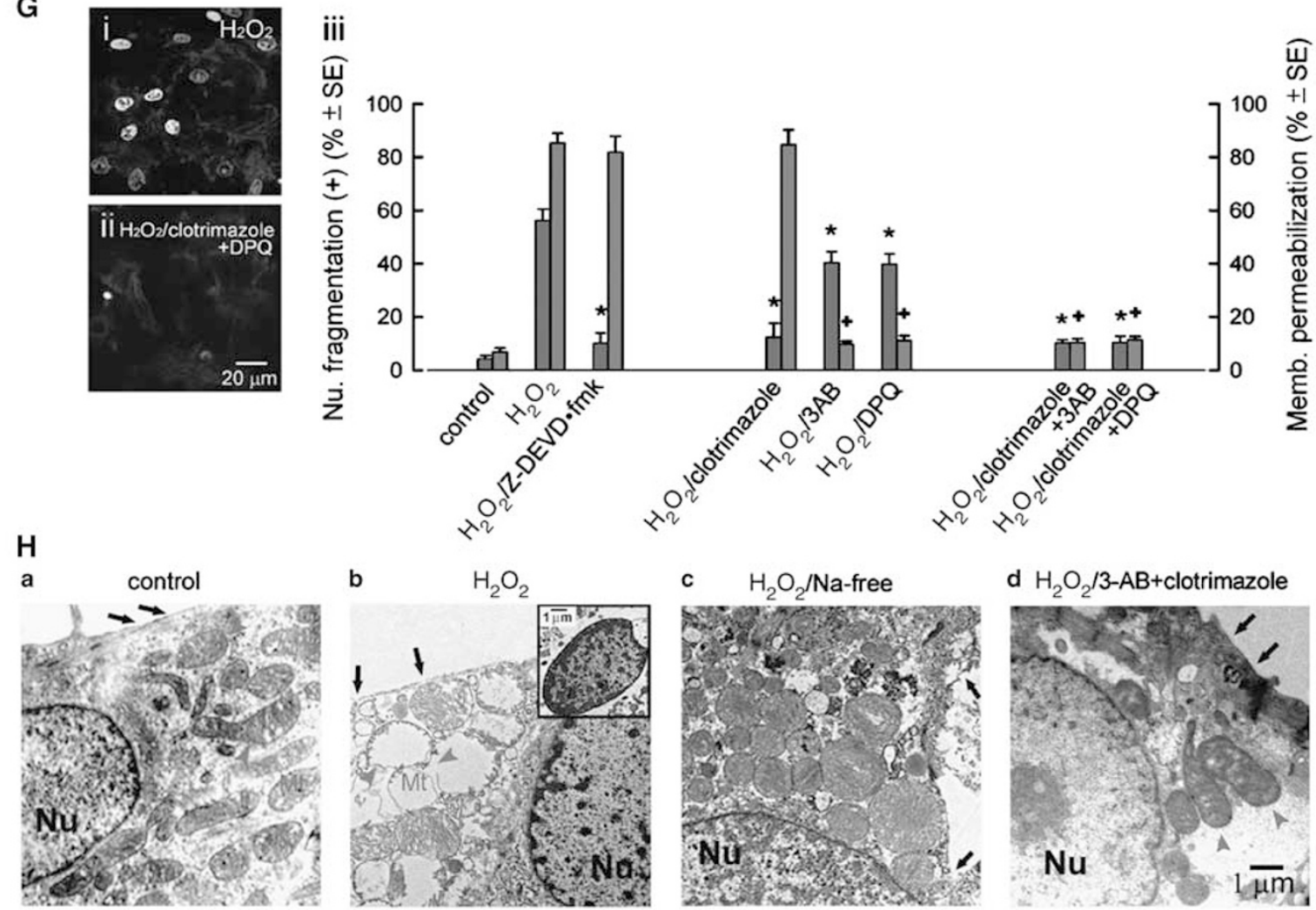
(oxidative stress)

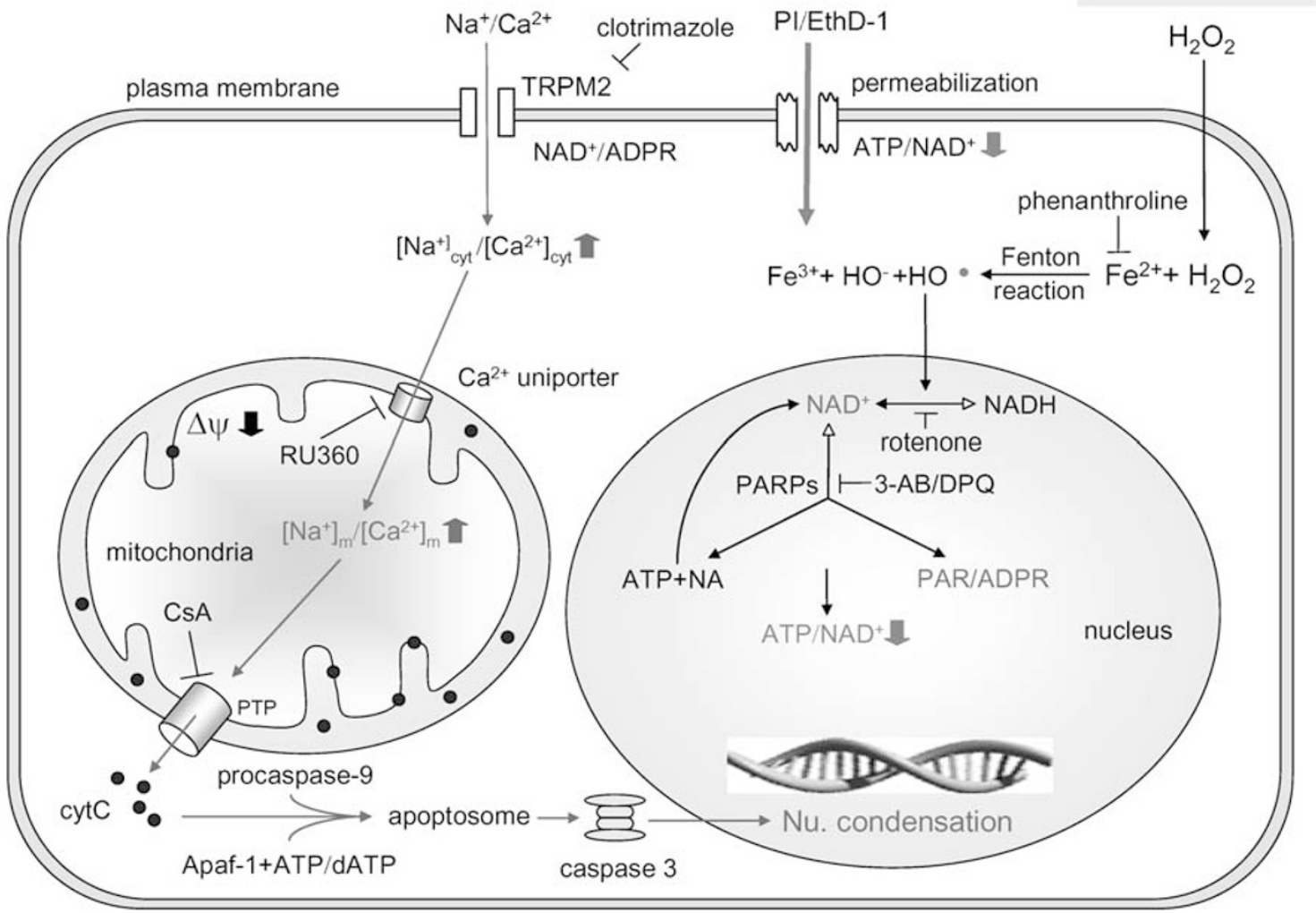

Figure 6 Possible molecular mechanism for $\mathrm{H}_{2} \mathrm{O}_{2}$-induced myocyte death. $\mathrm{OH}^{\bullet}$ induces an increase in $\mathrm{NAD}^{+} / \mathrm{ADPR}$ levels, resulting in an early TRPM2 opening, followed by $\left[\mathrm{Na}^{+}\right]_{\mathrm{m}} /\left[\mathrm{Ca}^{2+}\right]_{\mathrm{m}}$ overload, which induces CsA-sensitive PTP opening, ${ }^{4,11,33}$ apoptosome formation, and caspase 3-dependent nuclear condensation/ fragmentation. Intracellular ATP/NAD ${ }^{+}$are also depleted, due to $N A D^{+}$re-synthesis from ATP and nicotineamide (NA) ${ }^{13}$ resulting in membrane permeabilization and DNA fragmentation/condensation in a single myocyte

Na-free medium; Supplementary Figure S3Biii) was still present.

\section{Discussion}

After I/R insult, untypical apoptotic and necrotic ultrastructural features are both seen in the heart and brain. ${ }^{17-19}$ To our knowledge, this is the first report describing the molecular mechanisms involved in the two sets of death features in the same cell.

TRPM2 mRNA has been demonstrated in the heart. ${ }^{25,26}$ We here provide the first evidence that functional TRPM2 channels are present in the myocyte plasmalemma (Supplementary Figures S1 and S2). Firstly, a TRPM2 protein was expressed (Supplementary Figure S2D). Secondly, the electrophysiological properties seen following exposure to the specific TRPM2 messengers, $\mathrm{NAD}^{+}$and ADPR, were very similar (Supplementary Figures S1 and S2) to those seen in TRPM2-expressing cell lines. ${ }^{22-24,41}$ Moreover, a putative TRPM2 inhibitor, clotrimazole, ${ }^{42}$ completely inhibited the ADPR-induced current (Supplementary Figure S2Ab).

We also provided four lines of evidence that $\mathrm{H}_{2} \mathrm{O}_{2}$ activates TRPM2 via an increase in NAD ${ }^{+} /$ADPR levels, resulting in the $\left.\left[\mathrm{Ca}^{2+}\right]_{\mathrm{i}} /\left[\mathrm{Na}^{+}\right]_{\mathrm{i}} / \mathrm{Na}^{+}\right]_{\mathrm{m}}$ overload. Firstly, after exposure to $\mathrm{H}_{2} \mathrm{O}_{2}$, intracellular levels of $\mathrm{NAD}^{+}$and PAR/ADPR (see below) increased rapidly (Figure 1). Secondly, the electro- physiological properties of the $\mathrm{H}_{2} \mathrm{O}_{2}$-induced currents (Supplementary Figure $\mathrm{S} 3$ ) were very similar to those induced using specific TRPM2 messengers (Supplementary Figures S1 and S2). Thirdly, clotrimazole, a putative TRPM2 inhibitor, inhibited both the TRPM2-/ADPR-induced currents (Supplementary Figure $\mathrm{S} 2 \mathrm{Ab}$ ) and the $\mathrm{H}_{2} \mathrm{O}_{2}$-induced $\mathrm{Na}^{+} / \mathrm{Ca}^{2+}$ influx (Figure 5C). Fourthly, a decrease in the levels of both $\mathrm{NAD}^{+}$and PAR by either phenanthroline (Figure $1 \mathrm{~B}$ ) or rotenone (Figure 6) completely inhibited the $\mathrm{Na}^{+} / \mathrm{Ca}^{2+}$ influx (Figure 5A), while complete inhibition of an increase in PAR/ ADPR levels by $3-A B$ or DPQ (Figure 1Ed) had only a partial inhibitory effect on $\mathrm{Ca}^{2+} / \mathrm{Na}^{+}$influx (Figure $3 f$ and 5B). Our results therefore indicate that both $\mathrm{NAD}^{+}$and $\mathrm{ADPR}$ are involved in TRPM2 opening (Figure 6).

As reported by others, ${ }^{25}$ we showed that the TRPM2 was opened by mono(ADPR) (Supplementary Figure S2Ab). Since anti-PAR antibody only recognizes polymer (Figure 1D), ${ }^{32}$ it is difficult to know whether, following $\mathrm{H}_{2} \mathrm{O}_{2}$ exposure, mono(ADPR) levels increase, resulting in TRPM2 opening. When DNA is damaged by $\mathrm{H}_{2} \mathrm{O}_{2}$, the accumulated PAR undergoes rapid turnover, with a half-life of less than $1 \mathrm{~min}$, and is converted into mono(ADPR) by PARG. ${ }^{13,30,31}$ The partial inhibitory effect of $3-\mathrm{AB} / \mathrm{DPQ}$ on the $\mathrm{Na}^{+} / \mathrm{Ca}^{2+}$ influx (Figure $5 B$ ) therefore suggests that mono(ADPR) is probably produced by PARG, resulting in TRPM2 opening. However, other explanations cannot be ruled out. 
One important finding is that TRPM2 opening, resulting in the $\mathrm{Na}^{+} / \mathrm{Ca}^{2+}$ overload, is involved in the $\mathrm{H}_{2} \mathrm{O}_{2}$-activated apoptotic machinery. There is evidence that ROS-induced $\left[\mathrm{Ca}^{2+}\right]_{\mathrm{m}}$ overload is one of the major causes of myocyte apoptosis. ${ }^{4,11}$ However, under Ca-free conditions, in which the $\left[\mathrm{Ca}^{2+}\right]_{\mathrm{m}}$ overload should be totally abolished, nuclear condensation was only inhibited by $\sim 18 \%$ (Figure $2 \mathrm{~g}$ ). In addition to the $\left[\mathrm{Ca}^{2+}\right]_{\mathrm{m}}$ overload, the $\mathrm{H}_{2} \mathrm{O}_{2}$-induced $\left[\mathrm{Na}^{+}\right]_{\mathrm{m}}$ overload also plays an essential role in the activation of the apoptotic machinery, since (i) at least $50 \%$ of the $\left[\mathrm{Ca}^{2+}\right]_{i}$ overload originated from the $\mathrm{H}_{2} \mathrm{O}_{2}$-induced $\left[\mathrm{Na}^{+}\right]_{i}$ overload (Supplementary Figure S3Af), and Ca-free treatment did not inhibit either the $\left[\mathrm{Na}^{+}\right]_{\mathrm{i}}$ overload (Supplementary Figure $\mathrm{S} 3 \mathrm{Ag}$ ) or the $\left[\mathrm{Na}^{+}\right]_{\mathrm{cyt}} /\left[\mathrm{Na}^{+}\right]_{\mathrm{m}}$ overload (Figure $2 \mathrm{e}$ ), indicating that $\left[\mathrm{Na}^{+}\right]_{i}$ overload is an important upstream signal for $\left[\mathrm{Ca}^{2+}\right]_{\mathrm{i}}$ overload; (ii) when $\mathrm{H}_{2} \mathrm{O}_{2}-/ \mathrm{Na}$-ionoph-induced $\left[\mathrm{Na}^{+}\right]_{\mathrm{m}}$ overload, but not $\left[\mathrm{Na}^{+}\right]_{\text {cyt }}$ overload, was abolished, significant inhibition of nuclear condensation was seen (Figure 2g); and (iii) the EM study showed that Na-free treatment largely prevented the $\mathrm{H}_{2} \mathrm{O}_{2}$-induced mitochondrial membrane rupturing (Figure $5 \mathrm{Hc}$ ), which results in Na-sensitive cytC release.

High concentrations of $\mathrm{ROS} / \mathrm{H}_{2} \mathrm{O}_{2}$ induce PARP activation and $[\mathrm{ATP}]_{\mathrm{i}} / \mathrm{NAD}^{+}$depletion, leading to cardiac necrosis, and the use of $\mathrm{PARP}^{-1-}$ mice or PARP inhibitors reduces the infarct area (necrosis) by $\sim 20-25 \%,{ }^{13-15}$ indicating that other mechanisms may be involved (see below). EM analysis shows that the infarct area exhibits both necrotic and apoptotic changes, ${ }^{17,18}$ which are very similar to those seen in the present study (Figure $5 \mathrm{Hb}$ ). The present study showed that PARP inhibitors completely inhibited the caspase 3independent necrotic changes (Figure $3 \mathrm{~g}$ ), but had only a small protective effect ( 15-20\%, Figure 5F and Giii) on the caspase 3-dependent nuclear changes. The coactivation of the caspase-dependent and -independent cell death machineries clearly showed that different mechanisms are involved (Figure 6). One possible explanation is that caspase 3 activation occurs earlier than depletion of $[A T P]_{i}\left(\right.$ and NAD ${ }^{+}$) and $\mathrm{PI}$ influx (Figure $4 \mathrm{c}$ ), and the $[A T P]_{i}$ is therefore high enough for apoptosome formation to induce the apoptotic characteristics. ${ }^{12,40}$ Since PARP is normally cleaved/inactivated by activated caspase $3,,^{13}$ we may ask why $3-A B$ sensitive (Figure $3 \mathrm{~g}$ ), PARP-induced $[A T P]_{i}$ depletion still occurred after 40 min exposure to $\mathrm{H}_{2} \mathrm{O}_{2}$ (Figure 4c). One possible explanation is that maximum PARP activation (i.e. the peak level of PAR, Figure 1Ed) was seen as early as after 5-10 min exposure to $\mathrm{H}_{2} \mathrm{O}_{2}$, before caspase 3 activation, which started at $15 \mathrm{~min}$ and peaked at 30-40 min (Figure 4c). Since the resting level of the $[A T P]_{i}$ is $\sim 4-7 \mathrm{mM}$ in the heart, ${ }^{43}$ it may take time ( $\sim 40 \mathrm{~min}$ exposure, Figure $4 \mathrm{c}$ ) for it to be completely depleted by activated PARP. It should be noted that PARP/PAR activity starts to slowly decrease after $30 \mathrm{~min}$ exposure (Figure 1Ed), at the time when caspase 3 activity peaked ( $\sim 30-40$ min exposure, Figure $4 \mathrm{c}$ ).

Another important finding is that when TRPM2 and PARP activities were both inhibited by cotreatment with clotrimazole and $3-A B / D P Q$, both the ultrastructural and microscopic changes of the two sets of death features were largely prevented (Figure $5 \mathrm{G}$ and $\mathrm{Hd}$ ), showing a better protective effect $(>90 \%)$ than that seen when only PARP activity is inhibited (20-25\%). ${ }^{13-15}$ Further animal studies are needed to elucidate the therapeutic potential of the combination of PARP inhibitors and the widely used antifungal drug, clotrimazole, in providing better protection against I/R-induced injury.

\section{Materials and Methods}

Details of the following can be accessed in the expanded Methods section in Supplementary Materials: chemicals, external, and internal solutions; patch-clamp techniques; measurement of intracellular levels of NADH/ $\mathrm{NAD}^{+},\left[\mathrm{Na}^{+}\right]_{\mathrm{i}} /\left[\mathrm{Ca}^{2+}\right]_{\mathrm{i}}$, and ATP $\left([\mathrm{ATP}]_{\mathrm{i}}\right)$; immunochemical detection of PAR and TRPM2; in situ examination of apoptosis or necrosis; and EM.

\section{Preparation of neonatal rat ventricular myocytes}

All procedures were performed in accordance with the Animal Care Guidelines of the National Taiwan University. In brief, 1-day-old Wistar rats (both sexes) were killed by cervical dislocation, then decapitated, and ventricular myocyte cultures prepared as described previously. ${ }^{44}$

\section{Simultaneous measurement of $\left[\mathrm{Na}^{+}\right]_{\mathrm{cyt}}$ and $\left[\mathrm{Na}^{+}\right]_{\mathrm{m}}$ changes in a single ventricular myocyte using time- lapse confocal microscopy}

The detailed method is described in Supplementary Materials. A Leica SP confocal laser-scanning imaging system equipped with a $63 \times$ nicotinamide (NA) 1.32 oil immersion objective was used. The following equations $^{33}$ were used in Figure 2 to convert the $F / F_{0}\left(F_{0}=\right.$ basal fluorescence) into the $\left[\mathrm{Na}^{+}\right]_{\mathrm{cyt}}$ or $\left[\mathrm{Na}^{+}\right]_{\mathrm{m}}$, respectively:

(1) $\left[\mathrm{Na}^{+}\right]_{\mathrm{cyt}}=27.02\left[\mathrm{~F} / \mathrm{F}_{0}\right]-18.65$ (correlation coefficient $\left.=0.998\right)$

(2) $\left[\mathrm{Na}^{+}\right]_{\mathrm{m}}=43.47\left[\mathrm{~F} / F_{0}\right]-36.95$ (correlation coefficient $=0.997$ )

\section{Statistics}

In fluorescence measurement, all results are expressed as the mean \pm S.E.M. for the stated number of animal preparations $(n)$, each tested in duplicate. In immunostaining experiments, 200 cells from 10 randomly selected fields were scored on each coverslip; at least four animal preparations were used $(n=4)$ and duplicated in each test. Statistical differences were compared using the Mann-Whitney U-test, taking a $P$-value of $<0.05$ as significant.

\section{Acknowledgements}

We gratefully acknowledge the Second Core Laboratory of Department of Medical Research, National Taiwan University Hospital, and Major Instruments Co. Ltd (Chin-Yung Wang, Chin-Hsiang Wang, and WenChao Hsien) for expert technical assistance. We also thank the National Science Council of Taiwan (NSC 94-2320-B-002-005, NSC 94-2320-B002-061) for financial support.

\section{References}

1. Bolli R, Mohamed OJ, Patel BS, Aruoma OI, Halliwell B, Lai EK and McCay PB (1989) Marked reduction of free radical generation and contractile dysfunction by antioxidant therapy began at the time of reperfusion: evidence that myocardial 'stunning' is a manifestation of reperfusion injury. Circ. Res. 65: $607-622$ 
2. Colucci WS (1997) Molecular and cellular mechanisms of myocardial failure. Am. J. Cardiol. 80: 15L-25L

3. Saraste A, Pulkki K, Kallajoki M, Henriksen K, Parvinen M and Voipio-Pulkki L-M (1997) Apoptosis in human acute myocardial infarction. Circulation 95: 320-323

4. Crow MT, Mani K, Nam Y-J and Kitsis RN (2004) The mitochondrial death pathway and cardiac myocyte apoptosis. Circ. Res. 95: 957-970

5. Horwitz LD, Fennessey PV, Shikes RH and Kong Y (1994) Marked reduction in myocardial infarct size due to prolonged infusion of an antioxidant during reperfusion. Circulation 89: 1792-1801

6. Matsumura K, Jeremy RW, Schaper J and Becker LC (1998) Progression of myocardial necrosis during reperfusion of ischemic myocardium. Circulation 97: 795-804

7. Leist $M$ and Jäättelä $M$ (2001) Four deaths and a funeral: from caspases to alternative mechanisms. Nat. Mol. Cell Biol. 2: 1-10

8. Green D and Kroemer G (1998) The central executioners of apoptosis: caspases or mitochondria? Trends Cell Biol. 8: 267-271

9. Petronilli V, Penzo D, Scorrano L, Bernardi $P$ and Di Lisa $F$ (2001) The mitochondrial permeability transition, release of cytochrome $c$ and cell death. J. Biol. Chem. 276: 12030-12034

10. Newmeyer DD and Ferguson-Miller S (2003) Mitochondria: releasing power for life and unleashing the machineries of death. Cell 112: 481-490

11. Suleiman M-S, Halestrap AP and Griffiths EJ (2001) Mitochondria: a target for myocardial protection. Pharmacol. Ther. 89: 29-46

12. Leist M, Single B, Castoldi AE, Kuhnle $S$ and Nicotera $P$ (1997) Intracellular adenosine triphosphate (ATP) concentration: a switch in the decision between apoptosis and necrosis. J. Exp. Med. 185: 1481-1486

13. Virág $L$ and Szabó $C$ (2002) The therapeutic potential of poly(ADP-ribose) polymerase inhibitors. Pharmacol. Rev. 54: 375-429

14. Bowes J, McDonald MC, Piper J and Thiemermann C (1999) Inhibitors of poly(ADP-ribose) synthetase protect rat cardiomyocytes against oxidant stress. Cardiovasc. Res. 41: 126-134

15. Pieper AA, Walles T, Wei G, Clements EE, Verma A, Snyder SH and Zweier JL (2000) Myocardial postischemic injury is reduced by polyADPribose polymerase-1 gene disruption. Mol. Med. 6: 271-282

16. Buja LM and Entman ML (1998) Modes of myocardial cell injury and cell death in ischemic heart disease. Circulation 98: 1355-1357

17. Ohno M, Takemura G, Ohno A, Misao J, Hayakawa Y, Minatoguchi S, Fujiwara $T$ and Fujiwara $H$ (1998) Apoptotic myocytes in infarcts area in rabbit hearts may be oncotic myocytes with DNA fragmentation: analysis by immunogold electron microscopy combined with in situ nick end-labeling. Circulation 98: $1422-1430$

18. Dumont EAWJ, Hofstra L, van Heerde WL, van den Eijnde S, Doevendans PAF, DeMuinck E, Daemen MARC, Smits JFM, Frederik P, Wellens HJJ, Daemen MJAP and Reutelingsperger CPM (2000) Cardiomyocyte death induced by myocardial ischemia and reperfusion: measurement with recombinant human annexin-V in a mouse model. Circulation 102: 1564-1568

19. Van Lookeren Campagne M and Gill R (1996) Ultrastructural morphological changes are not characteristic of apoptotic cell death following focal cerebral ischemia in the rat. Neurosci. Lett. 213: 111-114

20. Montell C, Birnbaumer L and Flockerzi V (2002) The TRP channels, a remarkably functional family. Cell 108: $595-598$

21. Clapham DE (2003) TRP channels as cellular sensors. Nature 426: 517-524

22. Hara $Y$, Wakamori $M$, Ishii M, Maeno E, Nishida M, Yoshida T, Yamada $H$, Shimizu S, Mori E, Kudoh J, Shimizu N, Kurose H, Okada Y, Imoto K and Mori Y (2002) LTRPC2 $\mathrm{Ca}^{2+}$-permeable channel activated by changes in redox status confers susceptibility to cell death. Mol. Cell 9: 163-173

23. Wehage $E$, Eisfeld J, Heiner I, Jüngling $E$, Zitt $C$ and Lückhoff $A$ (2002) Activation of the cation channel long transient receptor potential channel 2 (LTRPC2) by hydrogen peroxide: a splice variant reveals a mode of activation independent of ADP-ribose. J. Biol. Chem. 277: 23150-23156

24. McHugh D, Flemming R, Xu S-Z and Perraud A-L (2003) Critical intracellular $\mathrm{Ca}^{2+}$ dependence of transient receptor potential melastatin 2 (TRPM2) cation channel activation. J. Biol. Chem. 278: 11002-11006
25. Perraud A-L, Fleig A, Dunn CA, Bagley LA, Launay P, Schmitz C, Stokes AJ, Zhu Q, Bessman MJ, Penner R, Kinet J-P and Scharenberg AM (2001) ADPribose gating of the calcium-permeable TRRPC2 channel revealed by nudix motif homology. Nature 411: 595-599

26. Sano $\mathrm{Y}$, Inamura $\mathrm{K}$, Miyake A, Mochizuki S, Yokoi $\mathrm{H}$, Matsushime $\mathrm{H}$ and Furuichi $\mathrm{K}$ (2001) Immunocyte $\mathrm{Ca}^{2+}$ influx system mediated by LTRPC2. Science 293: 1327-1330

27. Nieminen A-L, Byrne AM, Brian $\mathrm{H}$ and Lemasters JJ (1997) Mitochondria permeability transition in hepatocytes induced by $\mathrm{t}-\mathrm{BuOOH}$ : $\mathrm{NAD}(\mathrm{P}) \mathrm{H}$ and reactive oxygen species. Am. J. Physiol. 272: C1286-C1294

28. Filipovic DM, Meng $X$ and Reeves B (1999) Inhibition of PARP prevents oxidant-induced necrosis but not apoptosis in LLC-PK1 cells. Am. J. Physiol. 277: F428-F436

29. Ying W, Sevigny MB, Chen $Y$ and Swanson RA (2001) Poly(ADP-ribose) glycohydrolase mediated oxidative and excitotoxic neunal death. Proc. Natl. Acad. Sci. USA 98: 12227-12232

30. Alvarez-Gonzalez R and Althaus FR (1989) Poly(ADP-ribose) catabolism in mammalian cells exposed to DNA-damaging agents. Mutat. Res. 218: $67-74$

31. D'amours D, Desnoyers S, D'silva I and Poirier GG (1999) Poly(ADPribosyl)ation reactions in the regulation of nuclear functions. Biochem. J. 342 249-268

32. Küpper JH, de Murcia G and Bürkle A (1990) Inhibition of poly(ADPribosylation) by overexpressing the poly(ADP-ribose) polymerase DNA-binding domain in mammalian cells. J. Biol. Chem. 265: 18721-18724

33. Yang K-T, Pan S-F, Chien C-L, Hsu S-M, Tseng Y-Z, Wang S-M and Wu M-L (2004) Mitochondrial $\mathrm{Na}^{+}$overload is caused by oxidative stress and leads to activation of the caspase 3-dependent apoptotic machinery. FASEB J. 12: $1442-1444$

34. Chen Z, Alcayaga C, Suárez-Isla BA, O'Rourke B, Tomaselli G and Marbán E (2002) A 'minimal' sodium channel construct consisting of ligated S5-P-S6 segments forms a toxin-activatable ionophore. J. Biol. Chem. 277: 24653-24658

35. Chen W-H, Chu K-C, Wu S-J, Wu J-C, Shui H-A and Wu M-L (1999) Early metabolic inhibition-induced intracellular sodium and calcium increase in rat cerebellar granule cells. J. Physiol. (London) 515: 133-146

36. Collins TJ, Lipp P, Berridge MJ and Bootman MD (2001) Mitochondrial $\mathrm{Ca}^{2+}$ uptake depends on the spatial and temporal profile of cytosolic $\mathrm{Ca}^{2+}$ signals. J. Biol. Chem. 276: 26411-26420

37. Matlib MA, Zhou Z, Knight S, Ahmed S, Choi KM, Krause-Bauer J, Philips R, Altschuld R, Katsube Y, Sperelakis N and Bers DM (1998) Oxygen-bridged dinuclear ruthenium amine complex specifically inhibits $\mathrm{Ca}$ uptake into mitochondria in vitro and in situ in single cardiac myocytes. J. Biol. Chem. 273: 10223-10231

38. Gincel D, Zaid H and Shoshan-Barmatz V (2001) Calcium binding and translocation by the voltage-dependent anion channel: a possible regulatory mechanism in mitochondrial function. Biochem. J. 358: 147-155

39. McConkey DJ (1998) Biochemical determinants of apoptosis and necrosis. Toxicol. Lett. 42: 123-130

40. Jacobson MD, Weil M and Raff MC (1996) Role of Ced-3/ICE-family proteases in staurosporine-induced programmed cell death. J. Cell Biol. 133: 1041-1051

41. Zhang W, Chu X, Tong Q, Cheung JY, Conrad K, Masker K and Miller BA (2003) A novel TRPM2 isoform inhibits calcium influx and susceptibility to cell death. J. Biol. Chem. 278: 16222-16229

42. Hill K, McNulty S and Randall AD (2004) Inhibition of TRPM2 channels by the antifungal agents clotrimazole and econazole. Naunyn-Schmiedeberg's Arch. Pharmacol. 370: 227-237

43. Allen DG, Morris PG, Orchard CH and Pirolo JS (1985) A nuclear magnetic resonance study of metabolism in the ferret heart during hypoxia and inhibition of glycolysis. J. Physiol. (London) 361: 185-204

44. Wu M-L, Chen C-C and Su M-J (2000) Possible mechanism(s) of arachidonic acid-induced intracellular acidosis in rat cardiac myocytes. Circ. Res. 86: e55-e62

\section{Supplementary Information accompanies the paper on Cell Death and Differentiation website (http://www.nature.com/cdd)}

